\title{
Multi-characteristic optimization of WEDM for Ti-6Al-4V by applying grey relational investigation during profile machining
}

\author{
S. A. Sonawane*, B. P. Ronge, P. M. Pawar \\ SVERI's College of Engineering, Pandharpur-413304, Maharashtra, INDIA \\ Phone: +919850959863 \\ *Email: sonawanesachin09@gmail.com
}

\begin{abstract}
This research work presents multi-quality features optimization while wire electrical discharge machining (WEDM) of Ti-6Al-4V. Taguchi's L27 orthogonal arrangement is applied to inspect the outcome of governing variables such as pulse-on period, pulse-off interval, discharge voltage, discharge current, wire feed speed and cable tension on the kerf width, material removal rate (MRR), the surface roughness (SR) and overcut during intricate profile manufacturing on Ti-6Al-4V. To optimize all six governing variables, the grey relational investigation (GRI) is applied. The grey relational score is used as a multi-quality unique index (MQUI). From the experimental results the optimal configuration of governing variables obtained is pulse-on period $110 \mu \mathrm{s}$, pulse-off interval $55 \mu \mathrm{s}$, discharge voltage 40 volts, discharge current 170 Amp., wire feed speed $3 \mathrm{~m} / \mathrm{min}$ and cable tension 8 gram. ANOVA analysis indicates that pulse-on period is an essential variable concerning the quality outputs. Results of confirmation trials show that the optimal governing variables improved the grey relational score (GRS) from 0.9048 to 0.9226 for the multiple responses. SEM analysis of machined parts shows that at high values of pulse on period and discharge current, deep craters, globules of debris, voids, and micro cracks are formed on the cut surface thus deteriorating the surface finish.
\end{abstract}

Keywords: WEDM; Ti-6Al-4V; Taguchi method; grey relational investigation; grey relational score; profile machining; SEM analysis.

\section{INTRODUCTION}

WEDM is a thermal machining method in which material is removed by incessant sparks generated in a minute space between the wire electrode and workpiece in the existence of dielectric. It uses a thin wire made up of brass, copper, molybdenum, tungsten, or coated wire in the diameter range of $0.05-0.3 \mathrm{~mm}$ as an electrode and converts electrical power into thermal energy. This process is capable of achieving minimal corner radii up to $0.016 \mathrm{~mm}$ $0.13 \mathrm{~mm}$. After machining, the heat affected zone is tiny and lies in the range of $0.0025 \mathrm{~mm}$ $0.038 \mathrm{~mm}$. Also, due to negligible cutting forces allows it to obtain tight tolerances up to 2 microns. Thin sections can also be machined with a small amount of distortion. In WEDM there are many process parameters involved which are classified into electrical parameters 
and non-electrical parameters affecting the quality measures namely metal removal rate (MRR), surface finish, surface integrity, and dimensional accuracy. WEDM technology has been widely used in conductive material machining mainly for the production of mold, dies, medical and dental instrumentation, graphite electrodes, parts of automotive and aerospace industries [1]. The process output is a combination of electrodynamic, electromagnetic, thermal dynamic and hydrodynamic actions.

Jose and Shunmugum [2] studied the effect of WEDM process factors on surface finish and white layer thickness while machining Ti-6Al-4V. They found that the thickness of the white layer increases with an increase in the pulse on duration. Micro cracks were also observed in the white layer. Pasam et al. [3] studied surface finish characteristic during WEDM of Titanium grade-5. They considered different process factors such as ignition pulse current, injection pressure, short pulse duration, servo reference voltage, the time between two pulses, wire speed, servo speed, and wire tension. A genetic algorithm was employed for the optimization of the surface finish. Jabbaripour et al. [4] carried out electrical discharge machining of Ti-6Al-4V to study the influence of pulse on time, pulse current and open circuit voltage on TWR, MRR and recast layer thickness, microhardness and surface topography of the machined surface. From the results of experiments, it was found that the pulse on time was the major factor affecting MRR and TWR. Also, with an increase in pulse on time and pulse current density of micro holes, pits, and surface cracks were found to be increased. Kumar et al. [5] investigated four cutting performances, i.e. machining rate, dimensional deviation, surface finish, and wire wear ratio while machining titanium grade-2 alloy. The box-behnken design was used to perform the experiments. Mathematical relations were developed for the output characteristics. From the results of ANOVA, they found that pulse on time, pulse off time, servo voltage and peak current were the most significant factors affecting the performances. They also studied surface integrity aspects and material transfer phenomenon. Desirability function approach was used to carry out multi-response optimization. Chalisgaonkar and Kumar [6] performed experiments on pure titanium to find out the effect of on time, current, voltage, wire tension, wire feed and off time on surface roughness and cutting speed. Taguchi's $\mathrm{L}_{27}$ orthogonal design was applied to perform the experiments. Multi-characteristic optimization was carried out using the utility concept approach, and ANOVA results indicated that on time was the most significant variable affecting the outputs. Garg et al. [7] conducted WEDM operations on Ti-6-2-4-2 alloy. BoxBehnken design and response surface methodology were used to plan and analyze the experiments. Multi-objective optimization was performed using a desirability function approach. Mathematical models were also developed using RSM for cutting speed and surface roughness. Ghodsiyeh et al. [8] carried out WEDM of Ti-6Al-4V using RSM. The machining was performed using zinc coated brass wire. The input parameters considered were a pulse on time, pulse off time, peak current and servo voltage and the output features were surface roughness, sparking gap, wire lag, wire wear ratio, and white layer thickness. Empirical models were developed for output characteristics using RSM. Also, a desirability function approach was used to carry out multi-characteristics optimization. Sivaprakasm et al. [9] carried out micro-WEDM of Ti-6Al-4V. The experiments were performed using the RSM method central composite design. ANOVA results indicated that voltage and feed were the significant factors for kerf width, MRR, and surface roughness. Moreover, a genetic algorithm was applied for multi-objective optimization. Ramamurthy et al. [10] conducted tests on Titanium grade-5 with a pulse on time, wire tension, servo voltage, pulse off time 
and wire electrode type as input factors and kerf width, MRR and surface roughness as output parameters. They employed Taguchi based grey relational analysis for the multicharacteristics optimization. Pulse off time was found to be the significant factor affecting the performance measures. Kuriachen et al. [11] performed experiments on Ti-6Al-4V using micro-WEDM. They studied the effect of capacitance, gap voltage, wire tension and feed rate on MRR and surface roughness. A fuzzy-based modeling and particle swarm optimization was used for multi-objective optimization. Capacitance was found to be the prime factor affecting the performances. Majumdar and Maity [12] carried out an optimization of WEDM parameters for Titanium Grade-6. They used an integrated approach of PCA coupled with MOORA analysis. They found that the proposed optimization method involves less calculation as compared to other conventional methods. Raj and Prabhu [13] used Taguchi's L9 orthogonal array to determine the effect of pulse on time, pulse current and pulse off time on MRR and surface roughness using brass wire and molybdenum wire. From experimental results, it is found that pulse current and pulse on time have significant effect output features. PCA based Gray relational analysis was used for multi-feature optimization. Pujara et al. [14] carried out WEDM of Al-SiC composite. They investigated the influence of wire feed, pulse on time, peak current and pulse off time on kerf width and MRR. Taguchi based grey relational analysis was used for multi-characteristic optimization. Devarajaiah and Muthumari [15] studied the effect of current, pulse off time, wire speed and pulse on time on MRR and power consumption while WEDM of Ti-6Al-4V. They developed regression models for the outputs and used a desirability function approach for multiresponse optimization. Ali et al. [16] performed tests on stainless steel S304 using dry micro WEDM. They evaluated the influence of gap voltage and wire tension on dimensional accuracy.

Titanium and its alloys find broad applications in aerospace, chemical plant, automotive, power generation, surgery and medicine, oil and gas extraction, sports, etc. They possess enormous power, low density to weight ratio can withstand higher cutting temperatures, better corrosion resistance, very less thermal expansion coefficient, high rupture strength, and fatigue strength, can be applied at cryogenic temperatures, nonallergenic and fully biocompatible [17].

During conventional machining of titanium alloys, many problems occur such as the creation of higher mechanical stresses adjacent to the cutting boundary of the tool, chatter, uneven heat distribution in the tool, wear and tear of the flank and react chemically with all the tool materials at higher machining temperatures, etc. [18]. WEDM process can be effectively employed to machine such challenging to cut materials.

This paper presents the optimization of quality characteristics using grey relational study during composite profile machining of Ti-6Al-4V using wire EDM. Taguchi's $\mathrm{L}_{27}$ orthogonal table is used for testing to establish the most excellent governing variables combination. The levels of the controlling variables are evaluated following the four quality characteristics namely kerf width, MRR, surface roughness and overcut. Grey relational score is used to discover the influence of the governing variables on quality characteristics. SEM analysis of machined surfaces is performed to examine microstructures at low discharge energy and high discharge energy level. GRI provides a superb result to unsure, multi-factor and isolated problems. WEDM system is parallel; therefore GRI method can be effectively applied for the optimization of such kind of experimental work. 


\section{MATERIALS AND METHODS}

\section{Machine Tool and Work Material}

To attain the statistics for modeling, successive tests are carried out on a sprint cut WEDM (ePULSE-40) having 5-axis manufactured by Electronica Machine Tool Ltd., India. Figure 1 indicates the schematic diagram of the experimental setup and Figure 2 shows the actual test set up. During experimental setup, the dial indicator is used to ensure parallelism and perpendicularity of the workpiece concerning machine table. The work material decided in this exploration is Titanium grade-5 (Ti-6Al-4V) having chemical composition of $6 \% \mathrm{Al}$, $4 \% \mathrm{~V}, 0.25 \%(\max )$ iron, $0.2 \%$ (max) oxygen and rest titanium. A block of $30 \mathrm{~mm} \times 30 \mathrm{~mm}$ $\mathrm{x} 5 \mathrm{~mm}$ thick is used as a workpiece material connected to the anode. A brass wire of 0.25 $\mathrm{mm}$ diameter attached to the cathode is used to cut the intricate profile on the workpiece. Figure 3 shows the workpiece after WEDM. Such types of complex profiles are cut on the components which are used in aerospace and automobile industries. De-ionized water is used as a dielectric with a flushing pressure of $15 \mathrm{~kg} / \mathrm{cm}^{2}$ to clean the debris from the cutting region. The dielectric conductivity is retained at a steady value of $20 \mu \mathrm{S} / \mathrm{cm}$ at $25{ }^{\circ} \mathrm{C}$. All Trials are conducted at zero wire offset. The servo feed is kept at a constant value of 2120 units.

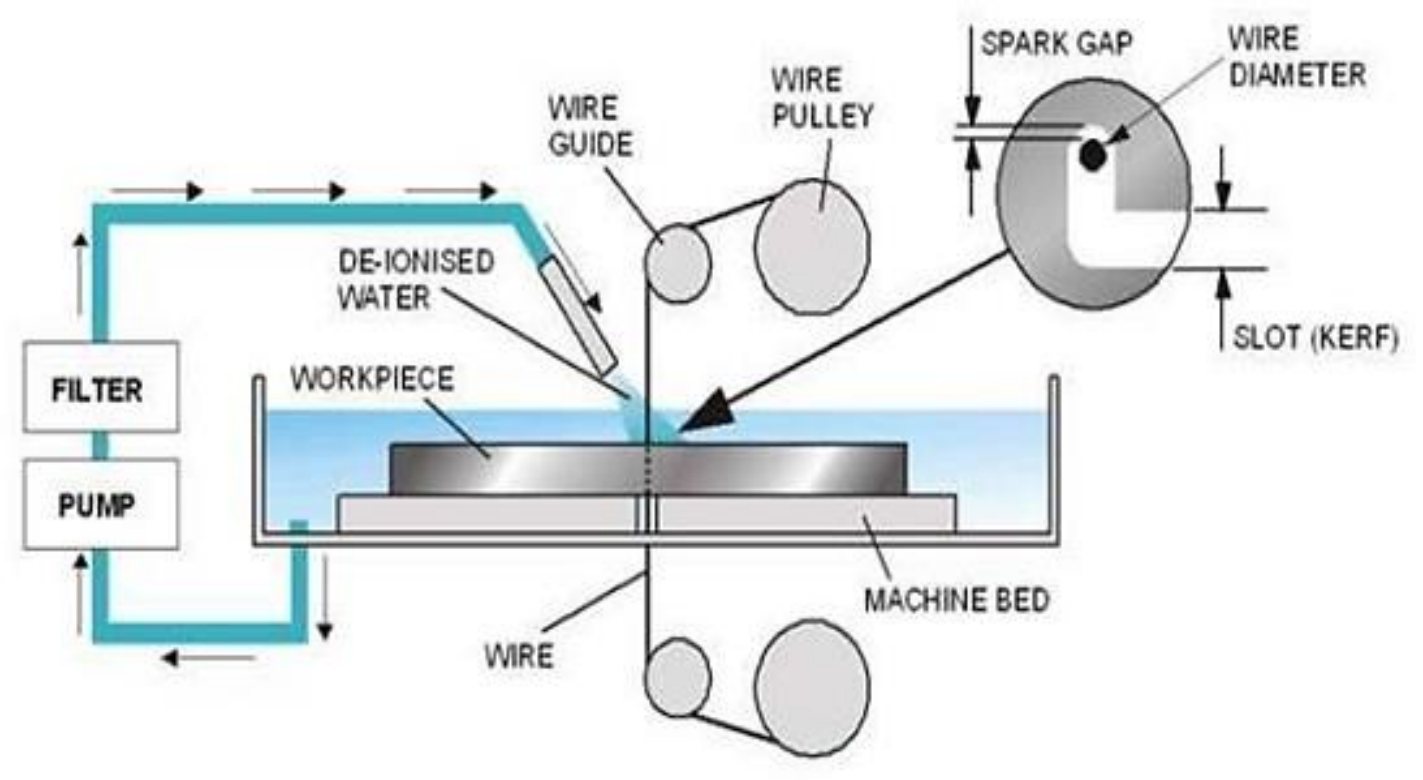

Figure 1. Schematic diagram of experimental set up [19]. 


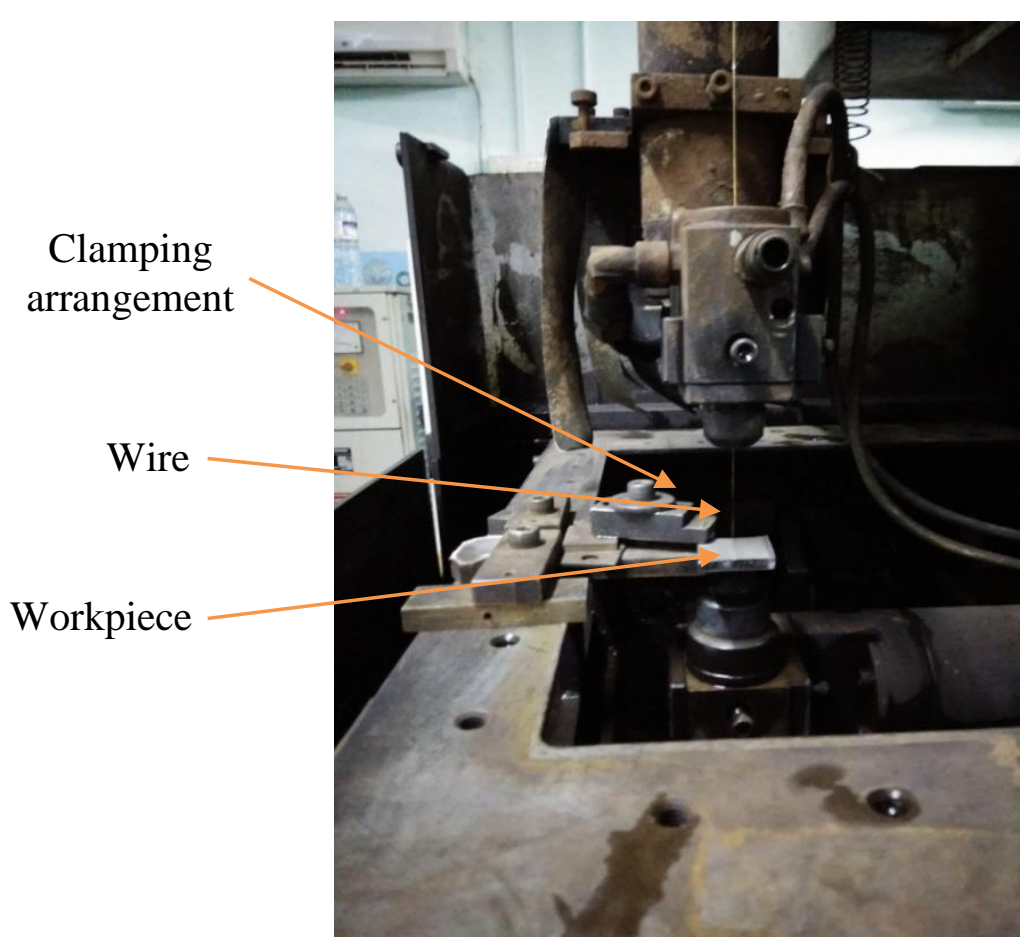

Figure 2. Test set up.

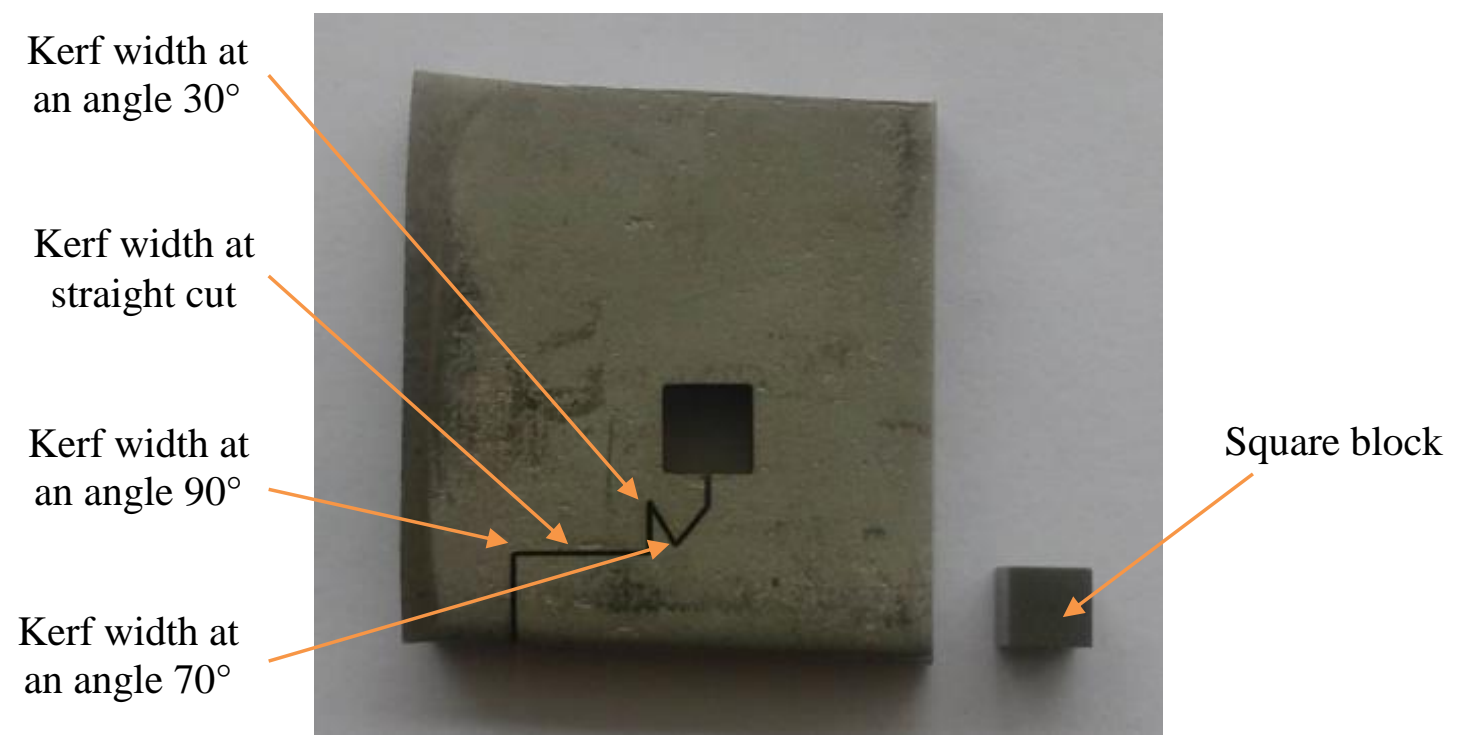

Figure 3. Workpiece after WEDM. 


\section{Assessment of Response Characteristics}

The following response characteristics are selected for the present research work:

Metal Removal Rate (MRR)

MRR is evaluated by finding the weight of the workpiece before and after cutting divided by machining time. The weight loss is then converted into the volume of material removed in $\mathrm{mm}^{3} / \mathrm{min}$ using the Equation. (1) [15].

$$
M R R=\frac{\text { Volume of material removed }}{\text { time taken in } \min }
$$

\section{Surface Roughness (SR)}

The surface roughness (Ra value) of the square block is assessed by using a Mitutoyo make digital surface tester SJ-210 in $\mu \mathrm{m}$. The surface finish is measured thrice on each cut surface perpendicular to the cut, and then the average value is obtained. The sampling length is considered as $0.8 \mathrm{~mm}$ during an assessment. Also, to examine the surface quality of the cut surfaces a scanning electron microscope (SEM) (JEOL 6300F, Japan) is used.

\section{Kerf Width}

The kerf width at four diverse places on the profile i.e. at straight cut (W1), at an angle $90^{\circ}$ (W2), $70^{\circ}(\mathrm{W} 3)$, and $30^{\circ}$ (W4) is measured by using a profile projector of 0.1 micron least count (Dr. Heinrich Schneider ST $360 \mathrm{H}$ German make). Kerf width is measured thrice at the respective locations as shown in Figure 3, and then the average is taken [16].

\section{Overcut}

It is the lateral space between the wire and workpiece during machining. Overcut [20] is determined by using Equation. (2).

$$
\text { Overcut }=\frac{\text { Magnitude of cut }-\mathrm{D}}{2}
$$

where, $D$ is the diameter of wire in $\mathrm{mm}$. The magnitude of the cut is the statistical variation of sizes between the square block and square on the workpiece. The dimension of the square on the workpiece is measured by a profile projector, and for that of the square, block is with a digital micrometer Mitutoyo make having an accuracy of 1 micron.

\section{Plan of Experiments}

In the present research, six governing variables are chosen such as pulse-on period, pulse-off interval, discharge voltage, discharge current, wire feed speed, and cable tension. To fix the proper range of governing factors, a sequence of preliminary tests are accomplished by varying one element at a moment while maintaining other factors steady at some value. Also, by taking reference of machine catalog, taking into consideration the thickness of the workpiece and the variation of quality characteristic, i.e., MRR about the cutting variables, the echelons of the governing factors are decided and are indicated in Table 1. 
Table 1. Governing variables and their levels.

\begin{tabular}{clcccc}
\hline Symbol & Governing Variable & Unit & Level 1 & Level 2 & Level 3 \\
\hline TON & Pulse on period & $\mu \mathrm{s}$ & 110 & 114 & 118 \\
TOFF & Pulse off interval & $\mu \mathrm{s}$ & 45 & 50 & 55 \\
SV & Discharge Voltage & Volts & 20 & 30 & 40 \\
IP & Discharge Current & Amp & 170 & 190 & 210 \\
WF & Wire Feed Speed & m/min & 1 & 3 & 5 \\
WT & Cable Tension & Gram & 2 & 5 & 8 \\
\hline
\end{tabular}

In the present research work, given six three-level factors and the interactions between three of them requires a total of 24 degrees of freedom (DOF). Therefore, Taguchi's $\mathrm{L}_{27}$ orthogonal table is used since it has $26 \mathrm{DOF}$, which is larger than 24 DOF in the selected governing parameters. Each trial is conducted three times; thus overall 81 tests are performed. Table 2 indicates the results of the Taguchi technique which are average of the three measurements of the performance characteristics. Minitab 16 software is employed for the statistical investigation.

The "lower-the-better" quality attribute (Equation. 3) is used for calculating the signal to noise ratio $(\mathrm{S} / \mathrm{N})$ of four kerf widths, surface roughness and overcut, whereas "higher-the better" quality feature (Equation. 4) for MRR.

$$
\begin{array}{r}
\text { S/N LB }=-10 \log \left[\frac{1}{n} \sum_{1}^{n} Y i j^{2}\right] \\
\text { S/N HB }=-10 \log \left[\frac{1}{n} \sum_{1}^{n} 1 / Y i j^{2}\right]
\end{array}
$$

where, Yij is the $\mathrm{i}^{\text {th }}$ experiment at the $\mathrm{j}^{\text {th }}$ test and $\mathrm{n}$ is the total number of repetitions. 
Table 2. Results of Taguchi's $\mathrm{L}_{27}$ orthogonal experiments

\begin{tabular}{|c|c|c|c|c|c|c|c|c|c|c|c|c|c|}
\hline $\begin{array}{c}\text { Exp. } \\
\text { No. }\end{array}$ & TON & TOFF & SV & IP & WF & WT & $\begin{array}{l}\text { W1 } \\
\text { mm }\end{array}$ & $\begin{array}{l}\mathrm{W} 2 \\
\mathrm{~mm}\end{array}$ & $\begin{array}{l}\text { W3 } \\
\text { mm }\end{array}$ & $\begin{array}{l}\text { W4, } \\
\text { mm }\end{array}$ & $\begin{array}{c}\text { Surface } \\
\text { Roughness } \\
(\mu \mathrm{m})\end{array}$ & $\begin{array}{l}\text { Overcut } \\
\text { (mm) }\end{array}$ & $\begin{array}{c}\text { MRR } \\
\left(\mathrm{mm}^{3} / \mathbf{m i n}\right)\end{array}$ \\
\hline 1 & 110 & 45 & 20 & 170 & 1 & 2 & 0.272 & 0.295 & 0.342 & 0.735 & 1.76 & 0.164 & 21.00 \\
\hline 2 & 110 & 45 & 20 & 170 & 3 & 5 & 0.258 & 0.277 & 0.322 & 0.72 & 1.53 & 0.161 & 18.26 \\
\hline 3 & 110 & 45 & 20 & 170 & 5 & 8 & 0.255 & 0.272 & 0.315 & 0.717 & 1.46 & 0.159 & 17.80 \\
\hline 4 & 110 & 50 & 30 & 190 & 1 & 2 & 0.265 & 0.286 & 0.332 & 0.728 & 1.68 & 0.163 & 20.16 \\
\hline 5 & 110 & 50 & 30 & 190 & 3 & 5 & 0.26 & 0.28 & 0.326 & 0.723 & 1.57 & 0.161 & 18.76 \\
\hline 6 & 110 & 50 & 30 & 190 & 5 & 8 & 0.255 & 0.271 & 0.313 & 0.715 & 1.45 & 0.159 & 17.72 \\
\hline 7 & 110 & 55 & 40 & 210 & 1 & 2 & 0.268 & 0.29 & 0.335 & 0.73 & 1.7 & 0.163 & 20.54 \\
\hline 8 & 110 & 55 & 40 & 210 & 3 & 5 & 0.254 & 0.269 & 0.308 & 0.71 & 1.41 & 0.158 & 17.50 \\
\hline 9 & 110 & 55 & 40 & 210 & 5 & 8 & 0.252 & 0.264 & 0.302 & 0.706 & 1.35 & 0.157 & 17.06 \\
\hline 10 & 114 & 45 & 30 & 210 & 1 & 5 & 0.294 & 0.324 & 0.38 & 0.768 & 2.29 & 0.172 & 28.23 \\
\hline 11 & 114 & 45 & 30 & 210 & 3 & 8 & 0.289 & 0.316 & 0.371 & 0.757 & 2.17 & 0.17 & 27.69 \\
\hline 12 & 114 & 45 & 30 & 210 & 5 & 2 & 0.275 & 0.297 & 0.346 & 0.736 & 1.8 & 0.164 & 22.00 \\
\hline 13 & 114 & 50 & 40 & 170 & 1 & 5 & 0.291 & 0.319 & 0.376 & 0.764 & 2.23 & 0.171 & 28.03 \\
\hline 14 & 114 & 50 & 40 & 170 & 3 & 8 & 0.27 & 0.292 & 0.339 & 0.732 & 1.73 & 0.164 & 20.60 \\
\hline 15 & 114 & 50 & 40 & 170 & 5 & 2 & 0.283 & 0.305 & 0.355 & 0.745 & 1.91 & 0.166 & 24.87 \\
\hline 16 & 114 & 55 & 20 & 190 & 1 & 5 & 0.278 & 0.3 & 0.351 & 0.74 & 1.86 & 0.166 & 23.57 \\
\hline 17 & 114 & 55 & 20 & 190 & 3 & 8 & 0.286 & 0.309 & 0.363 & 0.75 & 2 & 0.168 & 25.70 \\
\hline 18 & 114 & 55 & 20 & 190 & 5 & 2 & 0.28 & 0.303 & 0.353 & 0.741 & 1.88 & 0.166 & 24.65 \\
\hline 19 & 118 & 45 & 40 & 190 & 1 & 8 & 0.312 & 0.341 & 0.397 & 0.785 & 2.47 & 0.177 & 32.20 \\
\hline 20 & 118 & 45 & 40 & 190 & 3 & 2 & 0.285 & 0.307 & 0.361 & 0.748 & 1.97 & 0.168 & 25.37 \\
\hline 21 & 118 & 45 & 40 & 190 & 5 & 5 & 0.303 & 0.331 & 0.387 & 0.775 & 2.37 & 0.174 & 30.54 \\
\hline 22 & 118 & 50 & 20 & 210 & 1 & 8 & 0.287 & 0.314 & 0.367 & 0.752 & 2.09 & 0.169 & 27.38 \\
\hline 23 & 118 & 50 & 20 & 210 & 3 & 2 & 0.296 & 0.328 & 0.383 & 0.771 & 2.31 & 0.172 & 28.40 \\
\hline 24 & 118 & 50 & 20 & 210 & 5 & 5 & 0.29 & 0.318 & 0.372 & 0.76 & 2.2 & 0.17 & 27.79 \\
\hline 25 & 118 & 55 & 30 & 170 & 1 & 8 & 0.307 & 0.336 & 0.39 & 0.781 & 2.43 & 0.175 & 31.04 \\
\hline 26 & 118 & 55 & 30 & 170 & 3 & 2 & 0.293 & 0.321 & 0.378 & 0.766 & 2.27 & 0.173 & 28.00 \\
\hline 27 & 118 & 55 & 30 & 170 & 5 & 5 & 0.262 & 0.282 & 0.328 & 0.725 & 1.62 & 0.162 & 19.20 \\
\hline
\end{tabular}




\section{RESULTS AND DISCUSSION}

The influence of WEDM governing factors over performance characteristics, kerf width, surface roughness, MRR and overcut are analyzed and presented below:

\section{Effect of Governing Parameters on Kerf Width}

Figures 4 - 7 indicate that the kerf width increases with the increase in pulse on period and discharge current, and decreases with an increase in pulse off interval and discharge voltage. This is because as the pulse on period and discharge current increases; the discharge energy increases, which creates a large number of craters on the workpiece surface leading to increase in material removal and deteriorating surface finish. As the pulse off interval decreases, the number of discharges within a given time becomes more which leads to higher values of kerf width. With the increase in discharge voltage, the average discharge gap is widened resulting in a lower cutting rate [21]. The effect of wire tension on the kerf width is not very significant. From ANOVA Table 3 indicates that pulse on period, pulse off interval, discharge voltage, discharge current, and wire feed rate are essential parameters ( $p$ value $<0.05$ ) affecting the kerf width. It is observed that wire tension is the non-significant parameter for the kerf width.

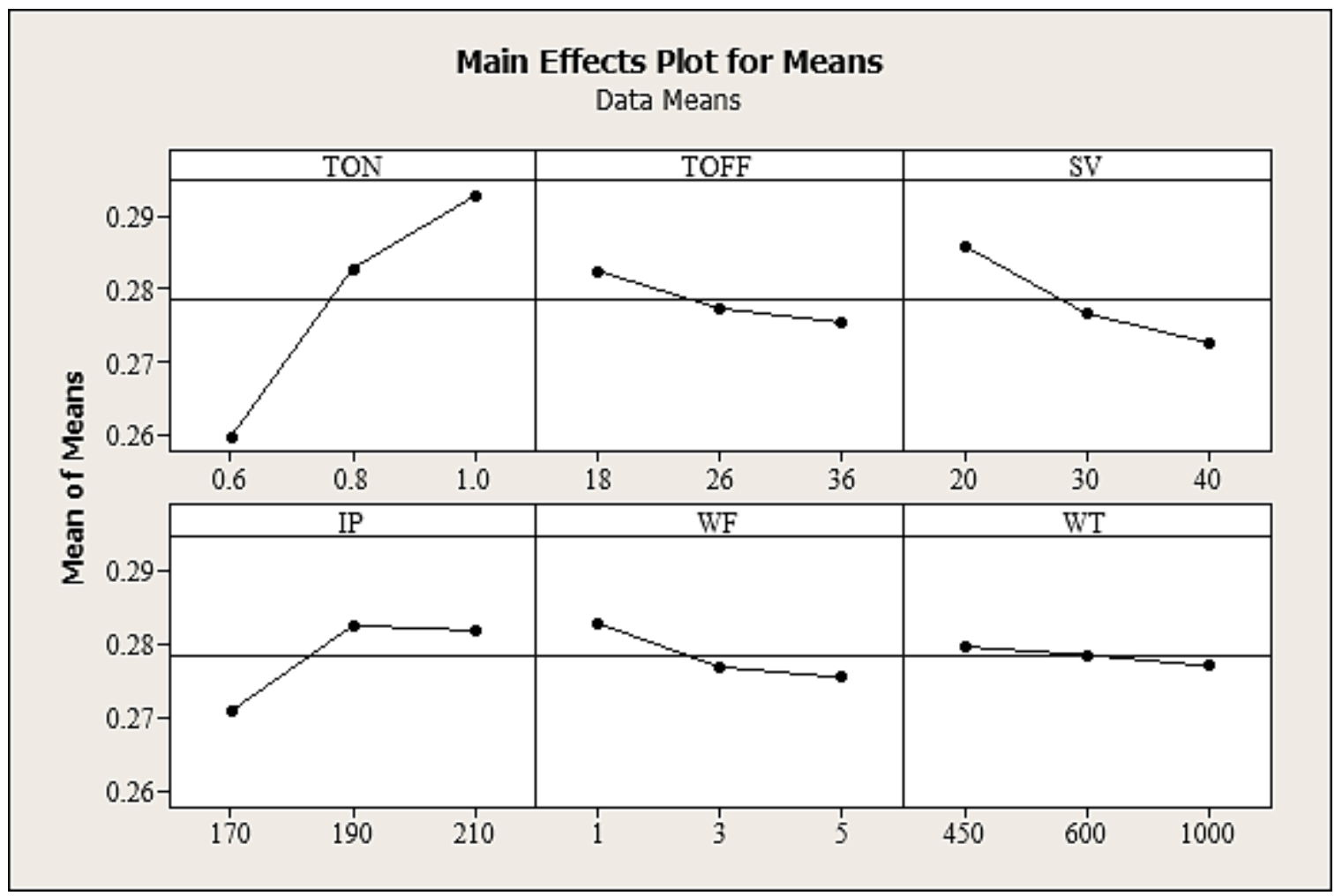

Figure 4. Effect of governing factors on kerf width at the straight cut (W1). 


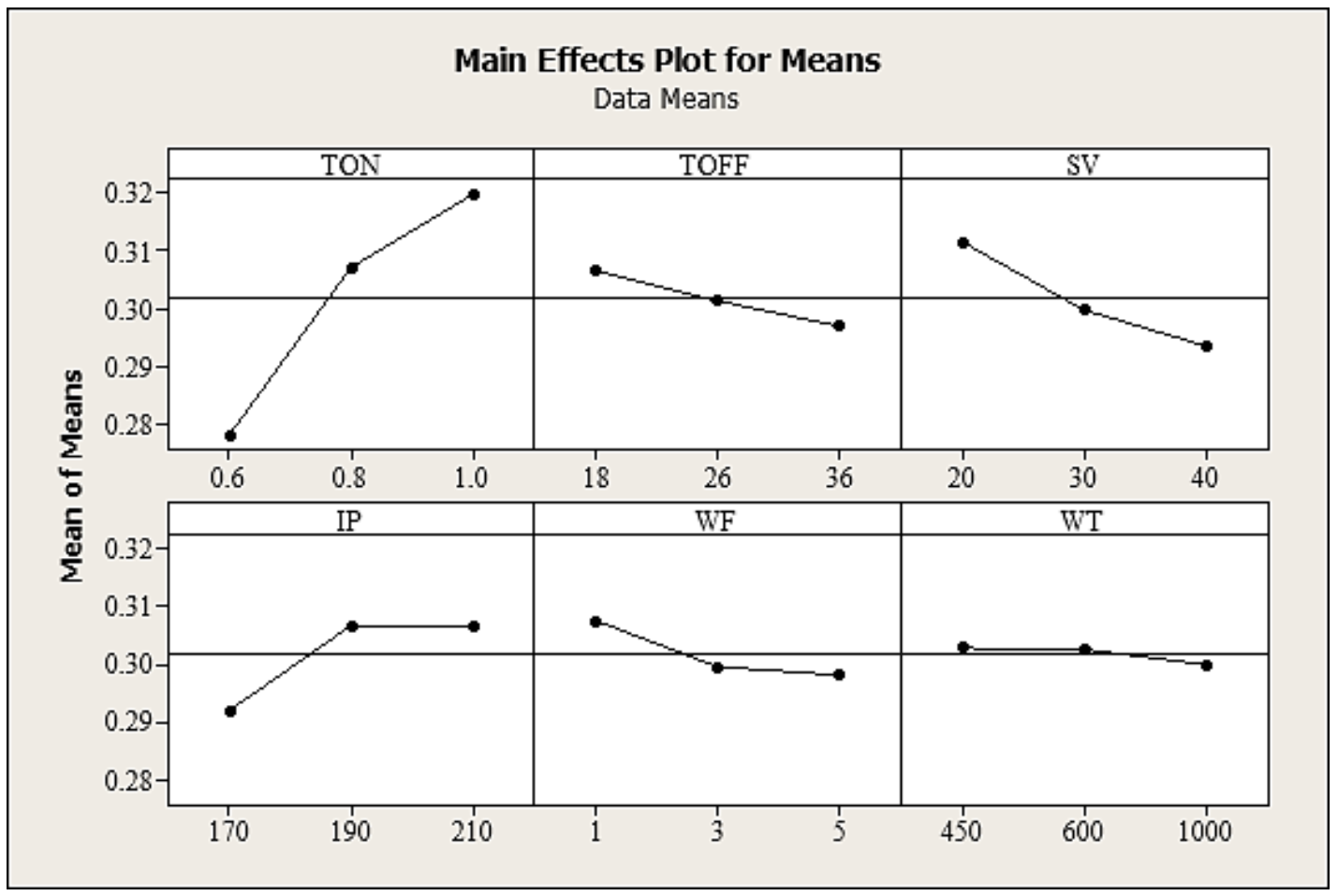

Figure 5. Effect of governing factors on kerf width at an angle $90^{\circ}$ (W2).

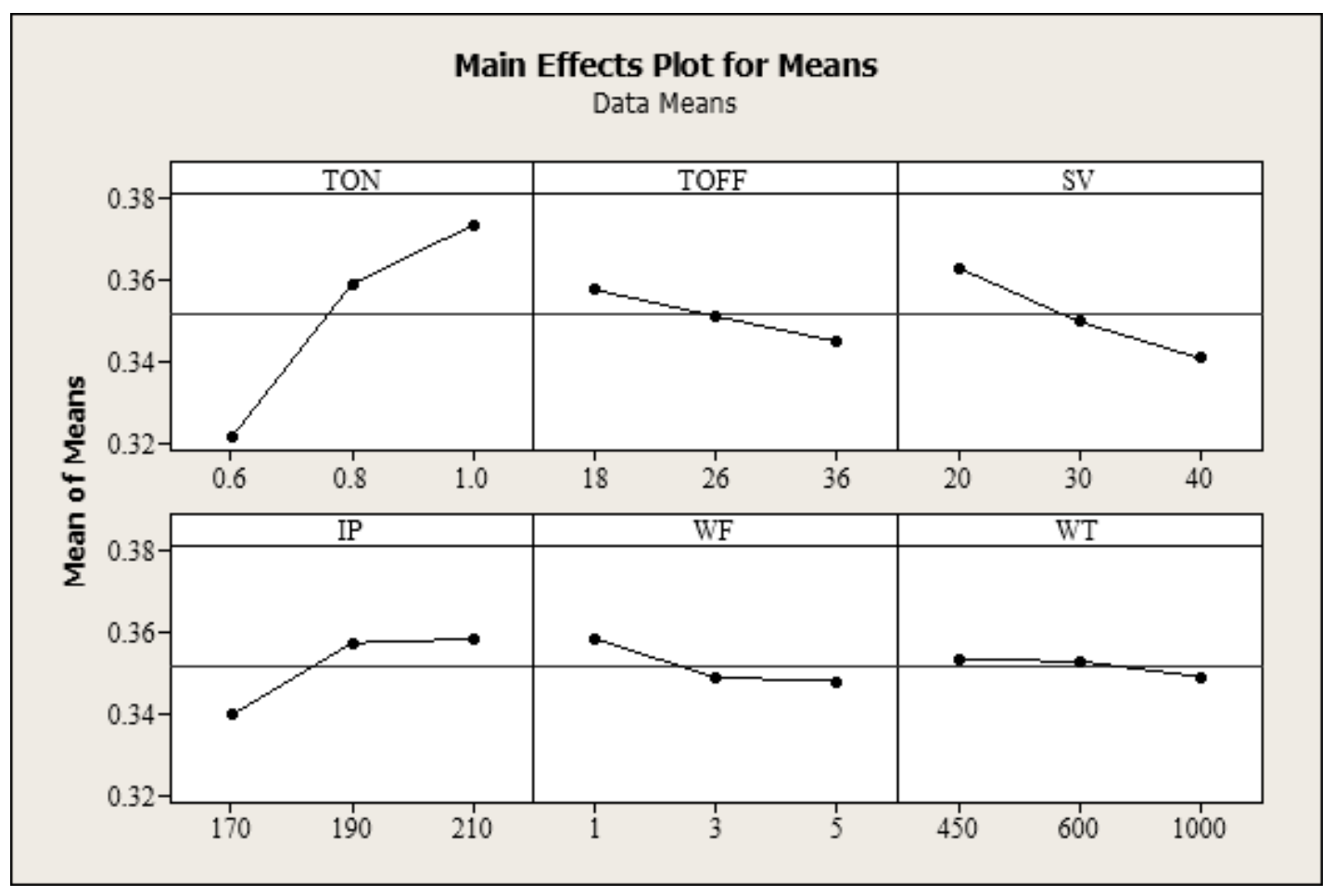

Figure 6. Effect of governing factors on kerf width at an angle $70^{\circ}$ (W3). 


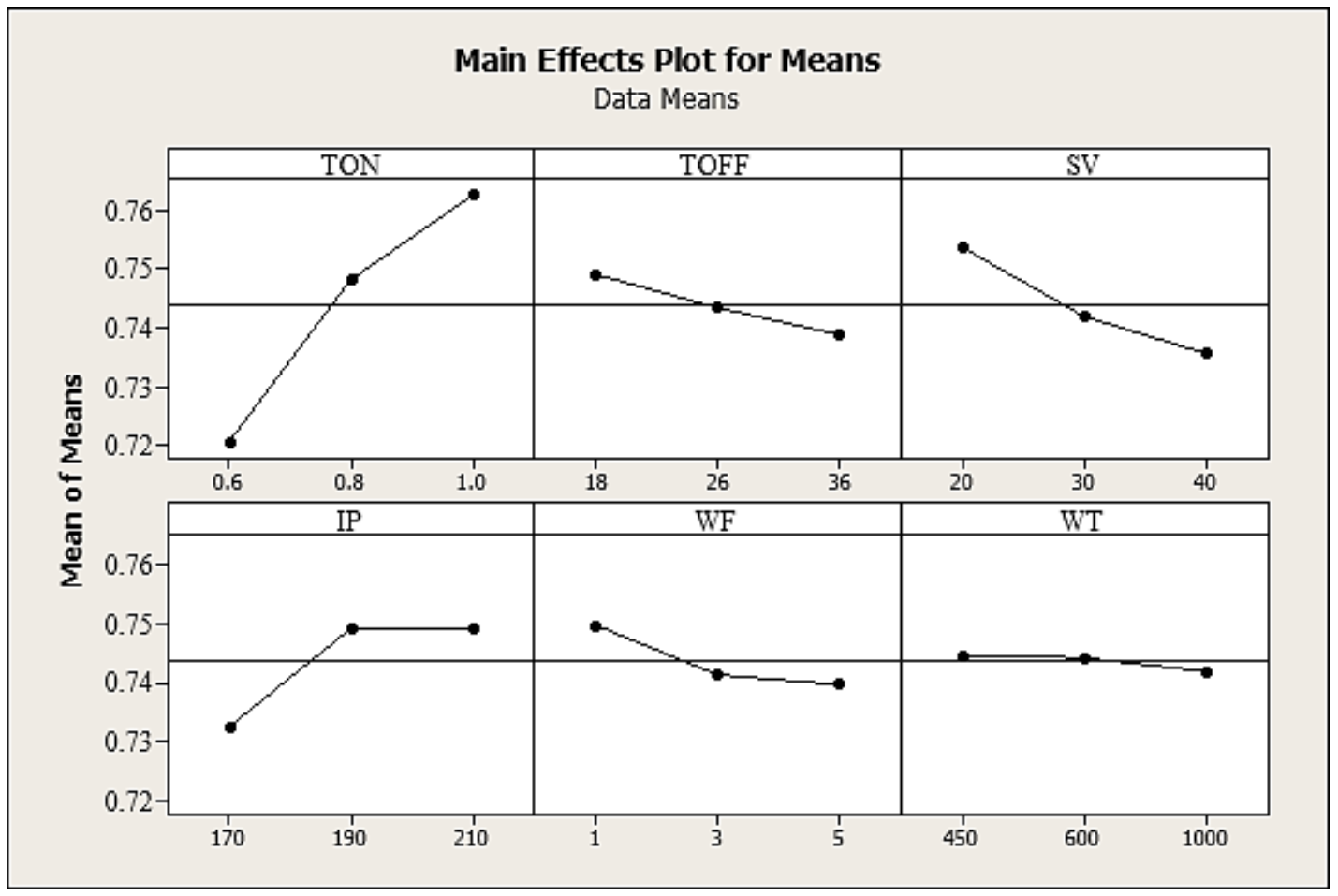

Figure 7. Effect of governing factors on kerf width at an angle $30^{\circ}$ (W4).

Table 3. ANOVA for kerf width W1, W2, W3 and W4.

\begin{tabular}{ccrrrr}
\hline Source & DF & Seq SS & Adj MS & \multicolumn{1}{c}{ F } & \multicolumn{1}{c}{ P } \\
\hline ANOVA for W1 & & & & & \\
TON & 2 & 5.04962 & 2.52481 & 246.12 & $0.004^{*}$ \\
TOFF & 2 & 0.22267 & 0.11134 & 10.85 & 0.084 \\
SV & 2 & 0.80951 & 0.40476 & 39.46 & $0.025^{*}$ \\
IP & 2 & 0.73271 & 0.36636 & 35.71 & $0.027^{*}$ \\
WF & 2 & 0.25719 & 0.1286 & 12.54 & 0.074 \\
WT & 2 & 0.0358 & 0.0179 & 1.74 & 0.364 \\
TON*TOFF & 4 & 0.07402 & 0.01851 & 1.8 & 0.387 \\
TON*SV & 4 & 0.06616 & 0.01654 & 1.61 & 0.417 \\
TOFF*SV & 4 & 0.27256 & 0.06814 & 6.64 & 0.135 \\
Residual & & & & & \\
Error & 2 & 0.02052 & 0.01026 & & \\
Total & 26 & 7.54077 & & & \\
R-Sq $=99.8 \%$ & $\mathrm{R}-S q(\operatorname{adj})=96.9 \%$ & & & \\
\hline
\end{tabular}




\begin{tabular}{crrrrr}
\hline Source & DF & \multicolumn{1}{c}{ Seq SS } & \multicolumn{1}{c}{ Adj MS } & \multicolumn{1}{c}{ F } & \multicolumn{1}{c}{ P } \\
\hline ANOVA for W2 & & & & & \\
TON & 2 & 0.008177 & 0.004088 & 398.49 & $0.003^{*}$ \\
TOFF & 2 & 0.000412 & 0.000206 & 20.08 & $0.047^{*}$ \\
SV & 2 & 0.001504 & 0.000752 & 73.31 & $0.013^{*}$ \\
IP & 2 & 0.00131 & 0.000655 & 63.86 & $0.015^{*}$ \\
WF & 2 & 0.000466 & 0.000233 & 22.7 & $0.042^{*}$ \\
WT & 2 & 0.000047 & 0.000023 & 2.27 & 0.306 \\
TON*TOFF & 4 & 0.000051 & 0.000013 & 1.25 & 0.49 \\
TON*SV & 4 & 0.000073 & 0.000018 & 1.78 & 0.391 \\
TOFF*SV & 4 & 0.000427 & 0.000107 & 10.4 & 0.09 \\
Residual & & & & & \\
Error & 2 & 0.000021 & 0.00001 & & \\
Total & 26 & 0.012487 & & & \\
R-Sq = 99.8\% & R-Sq(adj) $=97.9 \%$ & & & \\
\hline ANOVA for W3 & & & & & \\
TON & 2 & 0.012985 & 0.006492 & 276.92 & $0.004^{*}$ \\
TOFF & 2 & 0.00071 & 0.000355 & 15.13 & 0.062 \\
SV & 2 & 0.002228 & 0.001114 & 47.52 & $0.021^{*}$ \\
IP & 2 & 0.001985 & 0.000992 & 42.33 & $0.023^{*}$ \\
WF & 2 & 0.000585 & 0.000292 & 12.47 & 0.074 \\
WT & 2 & 0.000097 & 0.000048 & 2.07 & 0.326 \\
TON*TOFF & 4 & 0.000084 & 0.000021 & 0.89 & 0.589 \\
TON*SV & 4 & 0.000082 & 0.00002 & 0.87 & 0.596 \\
TOFF*SV & 4 & 0.000556 & 0.000139 & 5.92 & 0.15 \\
Residual & & & & & \\
Error & 2 & 0.000047 & 0.000023 & & \\
Total & 26 & 0.019357 & & & \\
R-Sq = 99.8\% & R-Sq(adj) $=96.9 \%$ & & & \\
\hline ANOVA for W4 & & & & & \\
TON & 2 & 0.008242 & 0.004121 & 682.64 & $0.001^{*}$ \\
TOFF & 2 & 0.000472 & 0.000236 & 39.1 & $0.025^{*}$ \\
SV & 2 & 0.001521 & 0.00076 & 125.93 & $0.008^{*}$ \\
IP & 2 & 0.001678 & 0.000839 & 138.96 & $0.007^{*}$ \\
WF & 2 & 0.000529 & 0.000264 & 43.81 & $0.022^{*}$ \\
WT & 2 & 0.00004 & 0.00002 & 3.32 & 0.232 \\
TON*TOFF & 4 & 0.000034 & 0.000008 & 1.4 & 0.456 \\
TON*SV & 4 & 0.000013 & 0.000003 & 0.56 & 0.722 \\
TOFF*SV & 4 & 0.000512 & 0.000128 & 21.22 & 0.046
\end{tabular}




\begin{tabular}{lrrr} 
Residual & 2 & 0.000012 & 0.000006 \\
$\begin{array}{l}\text { Error } \\
\quad \text { Total }\end{array}$ & 26 & 0.013054 & \\
R-Sq $=99.9 \%$ & $\mathrm{R}-\mathrm{Sq}(\mathrm{adj})=98.8 \%$ \\
\hline *P-value $<0.05$ indicates significant factor at $95 \%$ confidence level \\
\hline
\end{tabular}

\section{Effect of Governing Factors on Surface Roughness (SR)}

It is observed from the Figure 8 that surface roughness increases with the raising of the pulse on period, and discharge current and improves with the increase in pulse off interval, discharge voltage, and wire feed speed. The discharge energy increases with the pulse on period, and discharge current and more substantial discharge power produce a more massive crater, causing higher surface roughness value on the workpiece. As the pulse off interval diminishes, the number of discharges boosts which causes an increase in the values of surface roughness. With the growth in discharge voltage, the average discharge gap gets widened, and the amount of heat energy transferred to the workpiece decreases and less amount of material is melted and vaporized. This results in the formation of craters small size resulting in the decrease of surface roughness values due to stable machining [5-6]. With an increase in the wire feed speed, duration of contact between wire and workpiece decreases as the wire moves fast over the workpiece and workpiece is exposed to less amount of discharge energy resulting in less volume of material removal from the workpiece. Also, considering the thickness of the workpiece, as the wire speed increases, wire vibrations also increases and stability of the wire in the gap is adversely affected. Wire breakage occurs at these conditions. This results in unstable machining conditions and may result in uneven distribution of sparks in the gap. This leads to a decrease in surface roughness [7, 22]. The effects of cable tension are not very noteworthy. ANOVA Table 4 shows that pulse on period, discharge voltage, discharge current and wire feed speed are essential parameters $(p$-value $<0.05)$ affecting the surface roughness. It is observed that pulses off interval and wire tension are the nonsignificant parameter for surface roughness. 


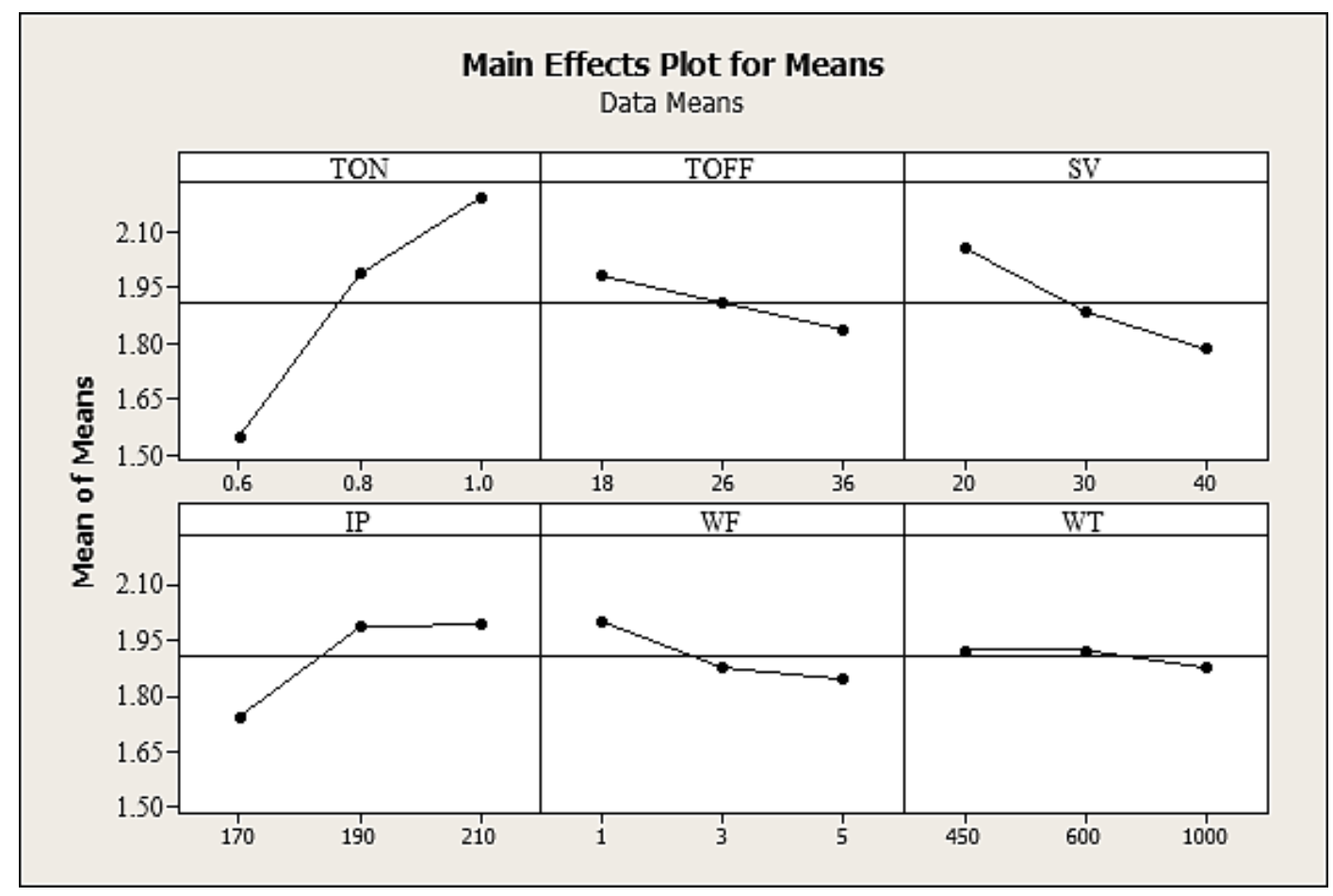

Figure 8. Effect of governing factors on surface roughness (SR).

Table 4. ANOVA for surface roughness (SR).

\begin{tabular}{crrrrr}
\hline Source & DOF & Seq. SS & Adj. MS & F & P-Value \\
\hline TON & 2 & 1.96347 & 0.981733 & 350.62 & $0.003^{*}$ \\
TOFF & 2 & 0.09389 & 0.046944 & 16.77 & 0.056 \\
SV & 2 & 0.34629 & 0.173144 & 61.84 & $0.016^{*}$ \\
IP & 2 & 0.36542 & 0.182711 & 65.25 & $0.015^{*}$ \\
WF & 2 & 0.12196 & 0.060978 & 21.78 & $0.044^{*}$ \\
WT & 2 & 0.01307 & 0.006533 & 2.33 & 0.3 \\
TON*TOFF & 4 & 0.01124 & 0.002811 & 1 & 0.554 \\
TON*SV & 4 & 0.00344 & 0.000861 & 0.31 & 0.855 \\
TOFF*SV & 4 & 0.09249 & 0.023122 & 8.26 & 0.111 \\
Residual & 2 & 0.0056 & 0.0028 & & \\
Error & & & & \\
Total & 26 & 3.01687 & & \\
\hline R-Sq $=99.8 \%$ & R-Sq(adj) $=97.6 \%$ \\
*P-value <0.05 indicates significant factor at 95\% confidence level \\
\hline
\end{tabular}




\section{Effect of Governing Factors on MRR}

It is found from the Figure 9 that MRR enhances with the increase of the pulse on period, and discharge current and reduces with the increase in pulse off interval, discharge voltage, and wire feed speed. As pulse on period, and discharge current raises, more amount of discharge energy is produced which results in further removal of material by melting and evaporation. With a small pulse off interval, the removal time for disintegrated particles from the gap being inadequate. The maximum MRR occurs which is due to the complete flushing of the disintegrated particles, and the complete de-ionized fluid is available for the next discharge. Further increase in pulse off interval value decreases the discharge frequency and increase the overall machining time [5-6]. With an increase in the wire feed speed, duration of contact between wire and workpiece decreases as the wire moves fast over the workpiece and workpiece is exposed to less amount of discharge energy resulting in less volume of material removal from the workpiece. Also, considering the thickness of the workpiece, as the wire speed increases, wire vibrations also increases and stability of the wire in the gap is adversely affected. Wire breakage occurs at these conditions. This results in unstable machining conditions and may result in uneven distribution of sparks in the gap. This leads to a decrease in MRR [7,22]. The effect of wire tension is not very notable.

ANOVA Table 5 shows that pulse on period, pulse off interval, discharge voltage, discharge current, and wire feed speed are essential parameters $(p$-value $<0.05)$ affecting the MRR. It is observed that wire tension is the non-significant parameter for MRR.

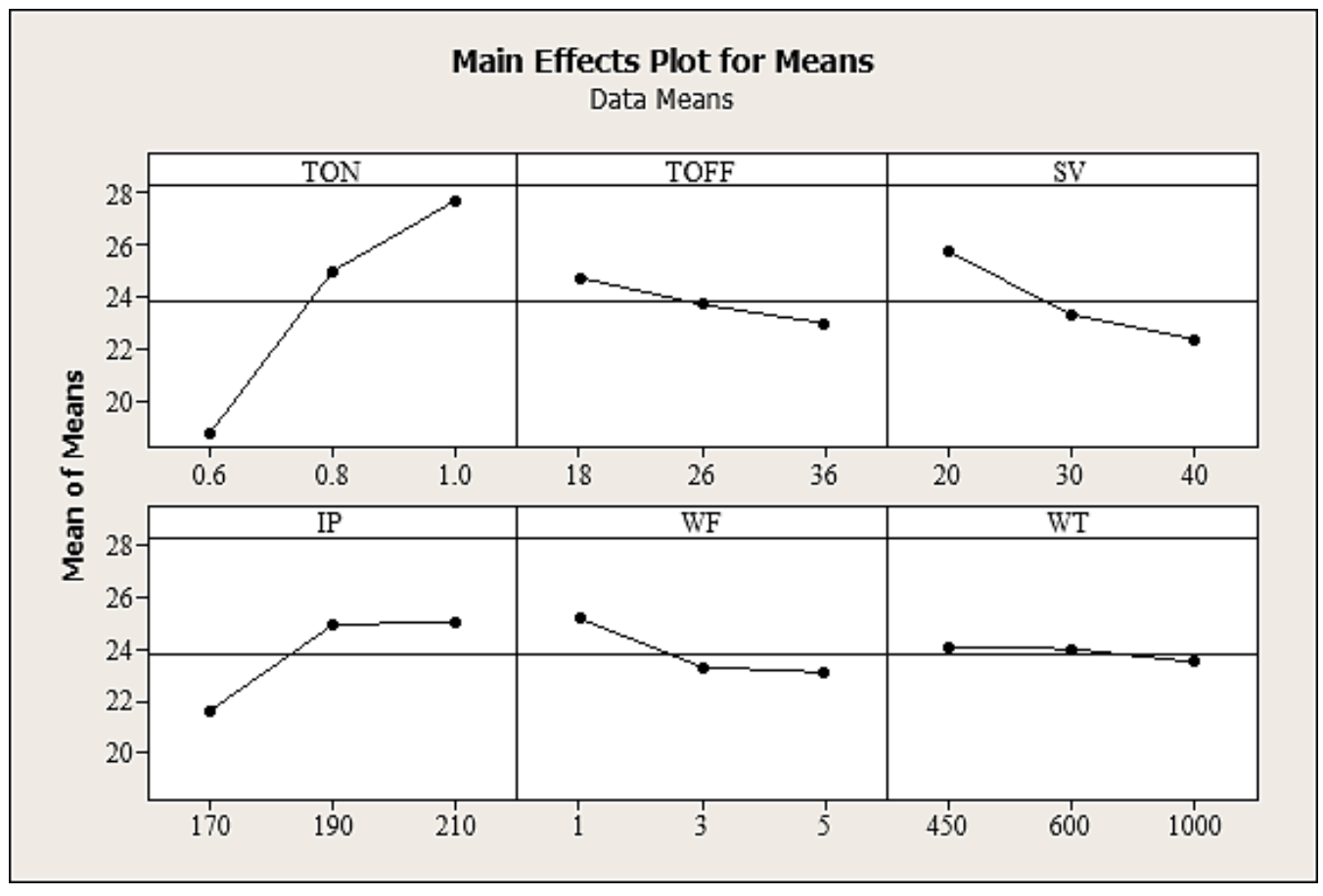

Figure 9. Effect of governing factors on MRR. 
Table 5. ANOVA for MRR.

\begin{tabular}{lrrrrr}
\hline Source & DOF & Seq. SS & Adj. MS & F & P-Value \\
\hline TON & 2 & 384.496 & 192.248 & 128.91 & $0.008^{*}$ \\
TOFF & 2 & 14.081 & 7.04 & 4.72 & 0.175 \\
SV & 2 & 54.985 & 27.492 & 18.43 & 0.051 \\
IP & 2 & 69.078 & 34.539 & 23.16 & $0.041^{*}$ \\
WF & 2 & 23.714 & 11.857 & 7.95 & 0.112 \\
WT & 2 & 1.85 & 0.925 & 0.62 & 0.617 \\
TON*TOFF & 4 & 6.868 & 1.717 & 1.15 & 0.514 \\
TON*SV & 4 & 2.282 & 0.57 & 0.38 & 0.812 \\
TOFF*SV & 4 & 16.706 & 4.177 & 2.8 & 0.28 \\
Residual & 2 & 2.983 & 1.491 & & \\
Error & \multicolumn{7}{c}{577.042} & & & \\
Total & 26 & & \\
\hline R-Sq $=99.5 \%$ & R-Sq(adj) = 93.3\% \\
*P-value $<0.05$ indicates significant factor at 95\% confidence level \\
\hline
\end{tabular}

\section{Effect of Governing Factors on Overcut (OC)}

It is found from Figure 10 that overcut first decreases sharply with the increase in pulse on period and then increases somewhat. As pulse off interval boosts, the overcut first amplifies and then diminishes. With the growth in discharge current and discharge voltage, decrement in the value of overcut is observed. Increasing cable tension value leads to elevated dimensional deviation. The effect of wire feed speed is not very noticeable. The forces acting on the wire electrode are the leading causes of the geometrical inaccuracy of the machined parts. The efficiency and the accuracy of the process are limited by the process parameters as well. Overcut value increases if the energy contained in a pulse increases to a considerable value. That's why when the pulse on period is very high the overcut increases. With the increase in cable tension the vibration and deflection of the wire changes resulting in the growth of overcut [23].

ANOVA Table 6 shows that pulse on time, peak current and wire tension are essential parameters $(p$-value $<0.05)$ affecting the overcut. It is observed that pulse off time, servo voltage and wire feed rate are the non-significant parameters for overcut. 


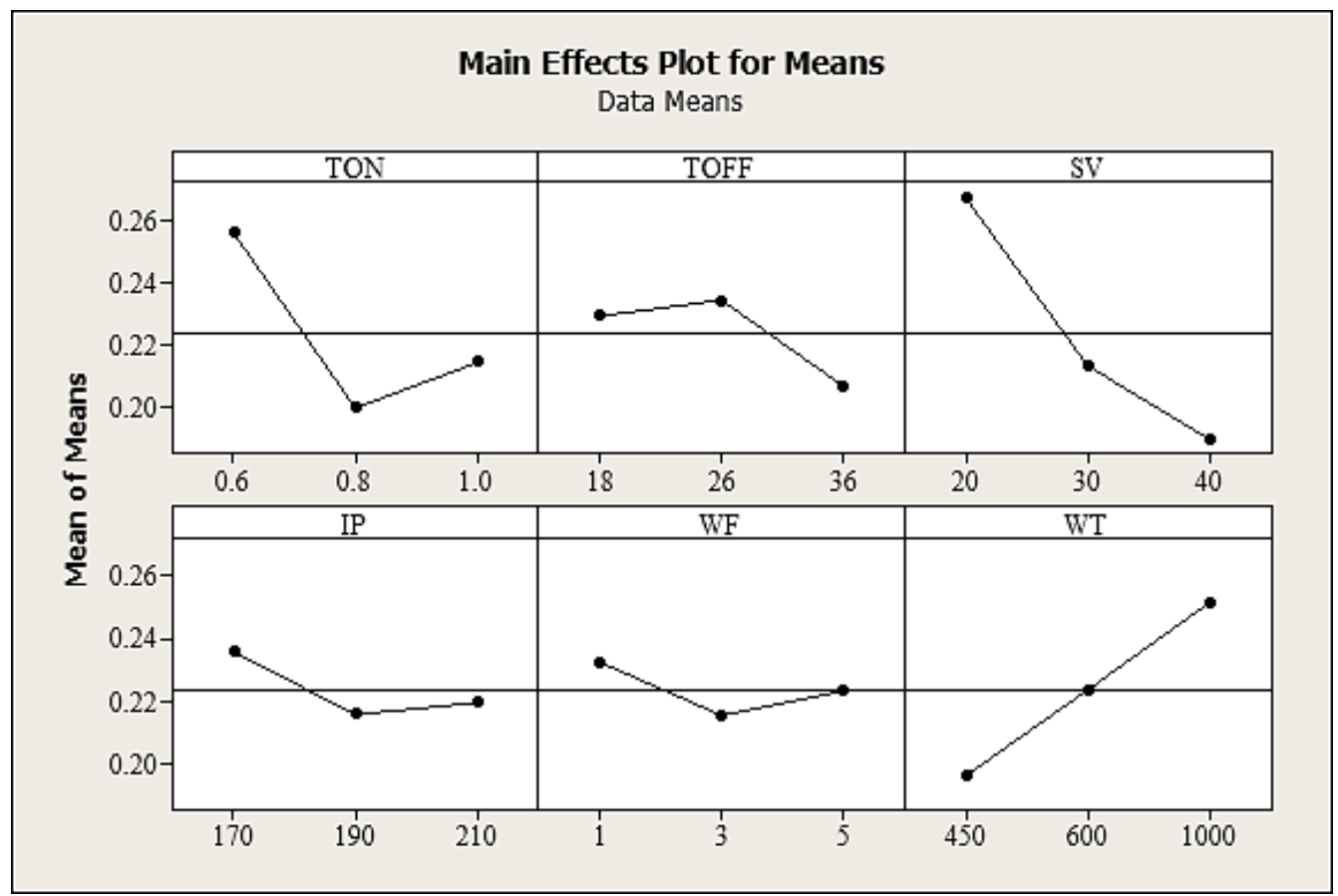

Figure 10. Effect of governing factors on overcut (OC).

Table 6. ANOVA for mean overcut (OC).

\begin{tabular}{ccrrrr}
\hline Source & DOF & \multicolumn{1}{l}{ Seq. SS } & \multicolumn{1}{c}{ Adj. MS } & \multicolumn{1}{l}{ F } & \multicolumn{1}{c}{ P-Value } \\
\hline TON & 2 & 0.015262 & 0.007631 & 134.4 & $0.007^{*}$ \\
TOFF & 2 & 0.003768 & 0.001884 & 33.18 & $0.029^{*}$ \\
SV & 2 & 0.028108 & 0.014054 & 247.52 & $0.004^{*}$ \\
IP & 2 & 0.002081 & 0.00104 & 18.32 & 0.052 \\
WF & 2 & 0.001305 & 0.000652 & 11.49 & $0.08^{*}$ \\
WT & 2 & 0.014001 & 0.007 & 123.3 & $0.008^{*}$ \\
TON*TOFF & 4 & 0.010371 & 0.002593 & 45.66 & $0.022^{*}$ \\
TON*SV & 4 & 0.000829 & 0.000207 & 3.65 & 0.226 \\
TOFF*SV & 4 & 0.001701 & 0.000425 & 7.49 & 0.121 \\
Residual & 2 & 0.000114 & 0.000057 & & \\
Error & \multicolumn{7}{c}{ R-Sq=99.9\% } & R-Sq(adj) = 98.1\% \\
Total & 26 & 0.077538 & & \\
\hline
\end{tabular}

$* \mathrm{P}$-value $<0.05$ indicates significant factor at $95 \%$ confidence level 
Multi-Quality Characteristic Optimization using Grey Relational Investigation (GRI) Grey theory was presented by Deng [24]. GRI is a multi-criteria assessment technique based on grey hypothesis. According to this approach, there are two categories of outputs namely, 'known' and 'unknown.' These results are represented as 'black' and 'white' respectively, in a grey hypothesis. The black indicates unknown data and white suggests known results. Other than black and white systems there may exist some incomplete data for all the experiments. This incomplete data is known as the grey system. When experimentations are ambiguous or if the trials cannot be performed correctly, grey investigation helps to compensate for the insufficiency in statistical regression. GRI is an efficient way of studying the correlation between experiments with less information and can explore various parameters that can overcome the limitations of an analytical technique [25].

Since in WEDM many factors are involved and is a transient process, therefore, can be regarded as a grey system. The theory of GRI is to evaluate the relationship and extent of closeness between the parameters based on the binary form of the several cycles [24].

In the present study, four quality characteristics that are required to be optimized by preferring suitable cutting conditions. They are kerf widths at four different locations, MRR, surface roughness and overcut. Such kind of problem is translated into a single objective optimization problem by applying grey relational investigation. The various steps involved in the grey relational study are as follows:

\section{Approach to the Present Research}

The WEDM process to be studied corresponds to 27 different tests. For the grey relational study, these 27 tests become 27 subsystems. The effect of these subsystems on the response characteristics is to be studied using the GRI system. Hence, the WEDM process is examined by performing 27 experiments where each trial is called a comparability sequence. The parametric setting related to the highest grey relational score provide the minimum values of the kerf width, surface roughness and is changed into a single characteristic optimization problem with the GRI method.

\section{Methodology}

The following stepwise approach is applied to explain the above formulation.

\section{Step1: Standardization of S/N ratio}

In this step, a standardization of $\mathrm{S} / \mathrm{N}$ is carried out to convert the original series into a comparable sequence. Table 7 shows the initial set of the $\mathrm{S} / \mathrm{N}$ ratio. For this purpose, a linear normalization of the $\mathrm{S} / \mathrm{N}$ ratio in the range of 0 to 1 is accomplished which is also called as the grey relational generating. The "smaller-the-better" and "Larger-the-better" is an attribute of the original run, and it is used to evaluate ranks in the GRA. Then the unique series is standardized using Equation. (5) and Equation. (6) and is indicated in Table 8.

Smaller-the-better

$$
\mathrm{Zi} *(\mathrm{k})=\frac{\max \mathrm{Zi}(\mathrm{k})-\mathrm{Zi}(\mathrm{k})}{\max \mathrm{Zi}(\mathrm{k})-\min \mathrm{Zi}(\mathrm{k})}
$$


Larger-the-better

$$
\mathrm{Zi} *(\mathrm{k})=\frac{\mathrm{Zi}(\mathrm{k})-\min \mathrm{Zi}(\mathrm{k})}{\max \mathrm{Zi}(\mathrm{k})-\min \mathrm{Zi}(\mathrm{k})}
$$

\section{Step 2: Calculation of Deviation Series}

The deviation sequence $\Delta 0_{\mathrm{i}}(\mathrm{k})$ is the numerical difference between the reference series $\mathrm{Z}_{0}{ }^{*}(\mathrm{k})$ and the comparability sequence $\mathrm{Z}_{\mathrm{i}}^{*}(\mathrm{k})$ after standardization. It is determined using Equation. 7 and is represented in Table 9.

$$
\Delta 0 \mathrm{i}(\mathrm{k})=|\mathrm{Z} 0 *(\mathrm{k})-\mathrm{Zi} *(\mathrm{k})|
$$

Step 3: Generation of Grey Relation Coefficient (GRC)

Grey relational coefficients are calculated as it states the relationship between the best (reference) and actual normalized $\mathrm{S} / \mathrm{N}$ ratio. GRC explains the relationship between the reference series $Z_{0}{ }^{*}(\mathrm{k})$ and the comparability sequence $\mathrm{Z}_{\mathrm{i}}^{*}(\mathrm{k})$. The GRC is calculated by using Equation. (8) and is shown in Table 10.

$$
\gamma \mathrm{i}(\mathrm{k})=\frac{\Delta \min +\zeta \cdot \Delta \max }{\Delta \min +\zeta \cdot \Delta \max }
$$

$0 \leq \gamma_{\mathrm{i}}(\mathrm{k}) \leq 1$

where,

$\Delta_{\min }=\min \left\{\min \Delta_{0, \mathrm{i}}(\mathrm{k})\right\}$

$\Delta_{\max }=\max \left\{\max \Delta_{0, \mathrm{i}}(\mathrm{k})\right\}$

In Equation. (8), $\zeta$ is the unique coefficient, $\zeta \in(0,1)$.

Step 4: Determination of Grey Relational Score (GRS)

The in general estimation of the multi-quality features is based on the grey relational score. GRS is an average summation of the grey relational coefficients which is defined as follows:

$$
\gamma\left(\mathrm{Z}_{0}, \mathrm{Z}_{\mathrm{i}}\right)=\frac{\sum_{\mathrm{i}=1}^{\mathrm{m}} \gamma\left\{\mathrm{Z}_{0}(\mathrm{k}), \mathrm{Z}_{\mathrm{i}}(\mathrm{k})\right\}}{\mathrm{m}}
$$

where, $\gamma\left\{Z_{0}(k), Z_{i}(k)\right\}$ is the grey relational score for the $\mathrm{j}^{\text {th }}$ trial and $\mathrm{m}$ is the number of quality characteristics. The GRS represents the degree of closeness among the reference series and comparability cycles. A higher value of GRS indicates a stronger union between the reference series and comparability cycles. The values of GRS are represented in Table 10. Thus, GRI is a measurement of the total amount of variation between results of sequences and it can be employed to measure close connection among the courses. 
Table 7. Original sequence of $\mathrm{S} / \mathrm{N}$ ratio.

\begin{tabular}{|c|c|c|c|c|c|c|c|}
\hline \multirow[b]{2}{*}{$\begin{array}{l}\text { Exp. } \\
\text { No. }\end{array}$} & \multicolumn{7}{|c|}{$\mathrm{S} / \mathrm{N}$ ratios } \\
\hline & $\begin{array}{r}\text { Kerf } \\
\text { width } \\
\text { W1 }\end{array}$ & $\begin{array}{r}\text { Kerf } \\
\text { width } \\
\text { W2 }\end{array}$ & $\begin{array}{r}\text { Kerf } \\
\text { width } \\
\text { W3 }\end{array}$ & $\begin{array}{r}\text { Kerf } \\
\text { width } \\
\text { W4 }\end{array}$ & $\begin{array}{r}\text { Surface } \\
\text { Roughness }\end{array}$ & Overcut & MRR \\
\hline 1 & 11.3191 & 10.6031 & 9.3278 & 2.678 & -4.8940 & 15.703 & 26.4160 \\
\hline 2 & 11.7186 & 11.1608 & 9.8516 & 2.8573 & -3.6947 & 15.8634 & 25.2297 \\
\hline 3 & 11.8805 & 11.3085 & 10.0331 & 2.8852 & -3.2694 & 15.9446 & 25.0082 \\
\hline 4 & 11.5449 & 10.8721 & 9.5859 & 2.7573 & -4.4890 & 15.7296 & 26.0912 \\
\hline 5 & 11.7116 & 11.0671 & 9.7445 & 2.8131 & -3.9188 & 15.8625 & 25.4646 \\
\hline 6 & 11.8805 & 11.3511 & 10.0795 & 2.9178 & -3.2096 & 15.9448 & 24.9707 \\
\hline 7 & 11.448 & 10.7619 & 9.4987 & 2.7295 & -4.5930 & 15.7549 & 26.2520 \\
\hline 8 & 11.903 & 11.4157 & 10.2288 & 2.9789 & -2.9639 & 15.9994 & 24.8607 \\
\hline 9 & 12.018 & 11.5783 & 10.4094 & 3.0238 & -2.6505 & 16.0812 & 24.6412 \\
\hline 10 & 10.6423 & 9.7889 & 8.4034 & 2.2962 & -7.1842 & 15.2642 & 29.0131 \\
\hline 11 & 10.8221 & 10.0154 & 8.6203 & 2.4141 & -6.7168 & 15.3909 & 28.8453 \\
\hline 12 & 11.2238 & 10.0149 & 9.2267 & 2.6624 & -5.0896 & 15.6767 & 26.8510 \\
\hline 13 & 10.732 & 9.9148 & 8.4959 & 2.3419 & -6.9535 & 15.34 & 28.9514 \\
\hline 14 & 11.3834 & 10.7021 & 9.4045 & 2.7097 & -4.7444 & 15.7028 & 26.2867 \\
\hline 15 & 10.9735 & 10.3233 & 9.0035 & 2.5529 & -5.6219 & 15.5975 & 27.9119 \\
\hline 16 & 11.1188 & 10.4671 & 9.102 & 2.6191 & -5.3769 & 15.5975 & 27.4483 \\
\hline 17 & 10.8827 & 10.2005 & 8.8097 & 2.6192 & -6.0211 & 15.4931 & 28.1998 \\
\hline 18 & 11.0669 & 10.3807 & 9.0526 & 2.6075 & -5.4837 & 15.5977 & 27.8360 \\
\hline 19 & 10.126 & 9.3533 & 8.0311 & 2.1062 & -7.8430 & 15.0403 & 30.1571 \\
\hline 20 & 10.9128 & 10.2666 & 8.8418 & 2.5257 & -5.8754 & 15.4937 & 28.0851 \\
\hline 21 & 10.3709 & 9.6121 & 8.2529 & 2.2138 & -7.4834 & 15.1883 & 29.6964 \\
\hline 22 & 10.8524 & 10.0701 & 8.7144 & 2.4717 & -6.3908 & 15.4422 & 28.7476 \\
\hline 23 & 10.5838 & 9.6912 & 8.3435 & 2.2587 & -7.2746 & 15.2893 & 29.0653 \\
\hline 24 & 10.7518 & 9.96 & 8.5967 & 2.3873 & -6.8354 & 15.3909 & 28.8777 \\
\hline 25 & 10.2568 & 9.4817 & 8.186 & 2.1506 & -7.7125 & 15.1391 & 29.8375 \\
\hline 26 & 10.6724 & 9.8786 & 8.4577 & 2.3191 & -7.1216 & 15.264 & 28.9421 \\
\hline 27 & 10.645 & 10.9948 & 9.6912 & 2.7892 & -4.1736 & 15.8096 & 25.6684 \\
\hline
\end{tabular}


Table 8 . The sequence after data processing.

\begin{tabular}{|c|c|c|c|c|c|c|c|}
\hline \multirow[b]{2}{*}{$\begin{array}{l}\text { Exp. } \\
\text { No. }\end{array}$} & \multicolumn{7}{|c|}{ Standardized S/N ratios } \\
\hline & $\begin{array}{r}\text { Kerf } \\
\text { width } \\
\text { W1 }\end{array}$ & $\begin{array}{r}\text { Kerf } \\
\text { width } \\
\text { W2 }\end{array}$ & $\begin{array}{r}\text { Kerf } \\
\text { width, } \\
\text { W3 }\end{array}$ & $\begin{array}{r}\text { Kerf } \\
\text { width, } \\
\text { W4 }\end{array}$ & $\begin{array}{r}\text { Surface } \\
\text { Roughness }\end{array}$ & Overcut & MRR \\
\hline 1 & 0.6306 & 0.5616 & 0.5452 & 0.6231 & 0.567935 & 0.6367 & 0.321761 \\
\hline 2 & 0.8734 & 0.8123 & 0.7654 & 0.8185 & 0.798902 & 0.7908 & 0.106692 \\
\hline 3 & 0.9273 & 0.8787 & 0.8417 & 0.8489 & 0.880809 & 0.8688 & 0.066535 \\
\hline 4 & 0.7499 & 0.6825 & 0.6537 & 0.7095 & 0.645932 & 0.6622 & 0.262876 \\
\hline 5 & 0.838 & 0.7702 & 0.7204 & 0.7704 & 0.755744 & 0.7899 & 0.149278 \\
\hline 6 & 0.9273 & 0.8978 & 0.8612 & 0.8845 & 0.892325 & 0.8689 & 0.059736 \\
\hline 7 & 0.6987 & 0.633 & 0.617 & 0.6792 & 0.625903 & 0.6866 & 0.292028 \\
\hline 8 & 0.9391 & 0.9268 & 0.924 & 0.951 & 0.939644 & 0.9214 & 0.039794 \\
\hline 9 & 1 & 1 & 1 & 1 & 1 & 1 & 0 \\
\hline 10 & 0.2728 & 0.1975 & 0.1565 & 0.207 & 0.126875 & 0.2151 & 0.7926 \\
\hline 11 & 0.3679 & 0.2975 & 0.2477 & 0.3355 & 0.21689 & 0.3369 & 0.762178 \\
\hline 12 & 0.5802 & 0.2973 & 0.5027 & 0.606 & 0.530265 & 0.6114 & 0.400624 \\
\hline 13 & 0.3202 & 0.2523 & 0.1954 & 0.2568 & 0.171305 & 0.2879 & 0.781414 \\
\hline 14 & 0.6645 & 0.6061 & 0.5774 & 0.6577 & 0.596745 & 0.6365 & 0.298319 \\
\hline 15 & 0.4479 & 0.4359 & 0.4088 & 0.4867 & 0.427752 & 0.5354 & 0.592959 \\
\hline 16 & 0.5247 & 0.5005 & 0.4502 & 0.5589 & 0.474935 & 0.5354 & 0.508911 \\
\hline 17 & 0.3999 & 0.3807 & 0.3273 & 0.559 & 0.350871 & 0.435 & 0.645153 \\
\hline 18 & 0.4973 & 0.4617 & 0.4295 & 0.5463 & 0.454367 & 0.5356 & 0.579198 \\
\hline 19 & 0 & 0 & 0 & 0 & 0 & 0 & 1 \\
\hline 20 & 0.4158 & 0.4104 & 0.3408 & 0.4571 & 0.378931 & 0.4356 & 0.624359 \\
\hline 21 & 0.1294 & 0.1163 & 0.0932 & 0.1172 & 0.069254 & 0.1423 & 0.916478 \\
\hline 22 & 0.3839 & 0.3221 & 0.2873 & 0.3983 & 0.279673 & 0.3861 & 0.744466 \\
\hline 23 & 0.2419 & 0.1518 & 0.1313 & 0.1661 & 0.109466 & 0.2393 & 0.802063 \\
\hline 24 & 0.3307 & 0.2726 & 0.2377 & 0.3063 & 0.194049 & 0.3369 & 0.768052 \\
\hline 25 & 0.0691 & 0.0577 & 0.0651 & 0.0483 & 0.025132 & 0.095 & 0.942058 \\
\hline 26 & 0.2888 & 0.236 & 0.1793 & 0.2319 & 0.138931 & 0.215 & 0.779728 \\
\hline 27 & 0.8028 & 0.7377 & 0.698 & 0.7442 & 0.706673 & 0.7391 & 0.186225 \\
\hline
\end{tabular}


Table 9. The deviation series for various quality characteristics.

\begin{tabular}{|c|c|c|c|c|c|c|c|}
\hline \multirow[b]{2}{*}{$\begin{array}{r}\text { Exp. } \\
\text { No. }\end{array}$} & \multicolumn{7}{|c|}{ Deviation Series } \\
\hline & $\begin{array}{r}\text { Kerf } \\
\text { width } \\
\text { W1 }\end{array}$ & $\begin{array}{r}\text { Kerf } \\
\text { width } \\
\text { W2 }\end{array}$ & $\begin{array}{r}\text { Kerf } \\
\text { width, } \\
\text { W3 }\end{array}$ & $\begin{array}{r}\text { Kerf } \\
\text { width W4 }\end{array}$ & $\begin{array}{r}\text { Surface } \\
\text { Roughness }\end{array}$ & Overcut & MRR \\
\hline 1 & 0.3694 & 0.4383 & 0.4548 & 0.3768 & 0.4321 & 0.3633 & 0.6782 \\
\hline 2 & 0.1266 & 0.1877 & 0.2345 & 0.1814 & 0.2011 & 0.2092 & 0.8933 \\
\hline 3 & 0.0727 & 0.1213 & 0.1582 & 0.1511 & 0.1192 & 0.1312 & 0.9335 \\
\hline 4 & 0.25 & 0.3174 & 0.3463 & 0.2904 & 0.3541 & 0.3378 & 0.7371 \\
\hline 5 & 0.1619 & 0.2298 & 0.2796 & 0.2296 & 0.2443 & 0.2101 & 0.8507 \\
\hline 6 & 0.0727 & 0.1021 & 0.1387 & 0.1155 & 0.1077 & 0.1311 & 0.9403 \\
\hline 7 & 0.3013 & 0.3669 & 0.3829 & 0.3207 & 0.3741 & 0.3134 & 0.708 \\
\hline 8 & 0.0608 & 0.0731 & 0.0759 & 0.049 & 0.0604 & 0.0786 & 0.9602 \\
\hline 9 & 0 & 0 & 0 & 0 & 0 & 0 & 1 \\
\hline 10 & 0.7271 & 0.8042 & 0.8435 & 0.7929 & 0.8731 & 0.7849 & 0.2074 \\
\hline 11 & 0.6321 & 0.7024 & 0.7523 & 0.6644 & 0.7831 & 0.6631 & 0.2378 \\
\hline 12 & 0.4198 & 0.7027 & 0.4973 & 0.3939 & 0.4697 & 0.3886 & 0.5994 \\
\hline 13 & 0.6797 & 0.7476 & 0.8046 & 0.7432 & 0.8287 & 0.7121 & 0.2186 \\
\hline 14 & 0.3354 & 0.3938 & 0.4225 & 0.3423 & 0.4033 & 0.3635 & 0.7017 \\
\hline 15 & 0.552 & 0.5641 & 0.5911 & 0.5132 & 0.5723 & 0.4646 & 0.407 \\
\hline 16 & 0.4753 & 0.4994 & 0.5497 & 0.441 & 0.5251 & 0.4646 & 0.4911 \\
\hline 17 & 0.6001 & 0.6192 & 0.6726 & 0.4409 & 0.6491 & 0.565 & 0.3549 \\
\hline 18 & 0.5027 & 0.5383 & 0.5705 & 0.4537 & 0.5456 & 0.4644 & 0.4208 \\
\hline 19 & 1 & 1 & 1 & 1 & 1 & 1 & 0 \\
\hline 20 & 0.5842 & 0.5896 & 0.6591 & 0.5429 & 0.6211 & 0.5644 & 0.3756 \\
\hline 21 & 0.8706 & 0.8837 & 0.9067 & 0.8827 & 0.9307 & 0.8577 & 0.0835 \\
\hline 22 & 0.6161 & 0.6778 & 0.7127 & 0.6017 & 0.7203 & 0.6139 & 0.2555 \\
\hline 23 & 0.758 & 0.8482 & 0.8687 & 0.8338 & 0.8905 & 0.7607 & 0.1979 \\
\hline 24 & 0.6693 & 0.7273 & 0.7622 & 0.6937 & 0.806 & 0.6631 & 0.2319 \\
\hline 25 & 0.9309 & 0.9423 & 0.9349 & 0.9516 & 0.9749 & 0.905 & 0.0579 \\
\hline 26 & 0.7112 & 0.7639 & 0.8206 & 0.768 & 0.8611 & 0.785 & 0.2203 \\
\hline 27 & 0.1972 & 0.2622 & 0.302 & 0.2557 & 0.2933 & 0.2609 & 0.8138 \\
\hline
\end{tabular}


Table 10. Grey relational coefficients and score values.

\begin{tabular}{|c|c|c|c|c|c|c|c|c|}
\hline \multirow[b]{2}{*}{$\begin{array}{l}\text { Exp. } \\
\text { No. }\end{array}$} & \multicolumn{7}{|c|}{ Grey Relational Coefficients (GRC) } & \multirow{2}{*}{$\begin{array}{r}\text { Grey } \\
\text { Relational } \\
\text { Score }(\text { GRS })\end{array}$} \\
\hline & $\begin{array}{r}\text { Kerf width } \\
\text { W1 }\end{array}$ & $\begin{array}{r}\text { Kerf } \\
\text { width } \\
\text { W2 } \\
\end{array}$ & $\begin{array}{r}\text { Kerf } \\
\text { width, } \\
\text { W3 } \\
\end{array}$ & $\begin{array}{r}\text { Kerf } \\
\text { width } \\
\text { W4 } \\
\end{array}$ & $\begin{array}{r}\text { Surface } \\
\text { Roughness }\end{array}$ & Overcut & MRR & \\
\hline 1 & 0.5751 & 0.5329 & 0.5236 & 0.5702 & 0.5364 & 0.5792 & 0.4243 & 0.5346 \\
\hline 2 & 0.798 & 0.7271 & 0.6806 & 0.7337 & 0.7131 & 0.705 & 0.3588 & 0.6738 \\
\hline 3 & 0.873 & 0.8047 & 0.7596 & 0.7679 & 0.8074 & 0.7921 & 0.3488 & 0.7363 \\
\hline 4 & 0.6666 & 0.6116 & 0.5908 & 0.6325 & 0.5854 & 0.5968 & 0.4041 & 0.584 \\
\hline 5 & 0.7553 & 0.6851 & 0.6413 & 0.6853 & 0.6718 & 0.7041 & 0.3701 & 0.6448 \\
\hline 6 & 0.873 & 0.8303 & 0.7828 & 0.8123 & 0.8227 & 0.7923 & 0.3471 & 0.7516 \\
\hline 7 & 0.6239 & 0.5767 & 0.5663 & 0.6092 & 0.572 & 0.6147 & 0.4139 & 0.5681 \\
\hline 8 & 0.8915 & 0.8724 & 0.8681 & 0.9108 & 0.8922 & 0.8642 & 0.3424 & 0.806 \\
\hline 9 & 1 & 1 & 1 & 1 & 1 & 1 & 0.3333 & 0.9048 \\
\hline 10 & 0.4074 & 0.3833 & 0.3721 & 0.3867 & 0.3641 & 0.3891 & 0.7068 & 0.43 \\
\hline 11 & 0.4416 & 0.4158 & 0.3992 & 0.4293 & 0.3896 & 0.4299 & 0.6776 & 0.4548 \\
\hline 12 & 0.5436 & 0.4157 & 0.5013 & 0.5593 & 0.5156 & 0.5627 & 0.4548 & 0.5076 \\
\hline 13 & 0.4238 & 0.4007 & 0.3832 & 0.4021 & 0.3763 & 0.4125 & 0.6958 & 0.4421 \\
\hline 14 & 0.5985 & 0.5593 & 0.5419 & 0.5936 & 0.5535 & 0.579 & 0.416 & 0.5489 \\
\hline 15 & 0.4752 & 0.4698 & 0.4582 & 0.4934 & 0.4663 & 0.5183 & 0.5512 & 0.4904 \\
\hline 16 & 0.5126 & 0.5002 & 0.4763 & 0.5313 & 0.4877 & 0.5183 & 0.5044 & 0.5045 \\
\hline 17 & 0.4545 & 0.4467 & 0.4263 & 0.5313 & 0.4351 & 0.4695 & 0.5848 & 0.4784 \\
\hline 18 & 0.4986 & 0.4815 & 0.467 & 0.5242 & 0.4781 & 0.5184 & 0.543 & 0.5016 \\
\hline 19 & 0.3333 & 0.3333 & 0.3333 & 0.3333 & 0.3333 & 0.3333 & 1 & 0.4286 \\
\hline 20 & 0.4611 & 0.4589 & 0.4313 & 0.4794 & 0.446 & 0.4698 & 0.571 & 0.474 \\
\hline 21 & 0.3648 & 0.3613 & 0.3554 & 0.3616 & 0.3494 & 0.3683 & 0.8568 & 0.4311 \\
\hline 22 & 0.4479 & 0.4245 & 0.4123 & 0.4538 & 0.4097 & 0.4489 & 0.6617 & 0.4656 \\
\hline 23 & 0.3974 & 0.3708 & 0.3653 & 0.3748 & 0.3595 & 0.3966 & 0.7163 & 0.4259 \\
\hline 24 & 0.4276 & 0.4073 & 0.3961 & 0.4188 & 0.3828 & 0.4299 & 0.6831 & 0.4494 \\
\hline 25 & 0.3494 & 0.3466 & 0.3484 & 0.3444 & 0.339 & 0.3559 & 0.8961 & 0.4257 \\
\hline 26 & 0.4128 & 0.3955 & 0.3786 & 0.3943 & 0.3673 & 0.3891 & 0.6941 & 0.4331 \\
\hline 27 & 0.7171 & 0.6559 & 0.6234 & 0.6616 & 0.6302 & 0.6571 & 0.3805 & 0.618 \\
\hline
\end{tabular}


Step 5: Selection of Optimal Level Parameters and ANOVA

The grey relational score obtained for each run is considered as an output for further investigation. Since a superior value of GRS indicates improved performance of the process, therefore more significant the better quality characteristic is utilized for the study of GRG. ANOVA is performed to establish the influence of each element in the response.

The response table is generated to find out the outcome of each rank of ruling variables on the grey relational score as shown in Table 11. The larger the value of GRS better is the particular multi-quality characteristic.

From the response Table, 11 of grey relational rating for the highest GRS, the best permutation of governing variables is set with $\mathrm{TON}_{1}(110), \mathrm{TOFF}_{3}(55), \mathrm{SV}_{3}(40), \mathrm{IP}_{1}(170)$, $\mathrm{WF}_{2}(3), \mathrm{WT}_{3}(8)$.

Table 11. Response table for GRS.

\begin{tabular}{cccclcc}
\hline Level & TON & TOFF & SV & IP & \multicolumn{1}{l}{ WF } & WT \\
\hline 1 & 0.6893 & 0.5190 & 0.4870 & 0.5790 & 0.5304 & 0.5402 \\
2 & 0.4843 & 0.5336 & 0.5489 & 0.5382 & 0.5594 & 0.5338 \\
3 & 0.4613 & 0.5822 & 0.5990 & 0.5176 & 0.5451 & 0.5609 \\
Delta & 0.2281 & 0.0633 & 0.112 & 0.0613 & 0.029 & 0.0272 \\
\hline
\end{tabular}

Step 6: ANOVA and Confirmation Experiments

Analysis of variance (ANOVA) is applied to decide primary influencing factors and percentage contribution of governing variables for GRS. The results of ANOVA are represented in Table 12.

Table 12. ANOVA for GRS.

\begin{tabular}{ccrrrrr}
\hline Source & DOF & Sq. SS & Adj. MS & \multicolumn{1}{c}{ F } & P-value & $\begin{array}{c}\text { \% } \\
\text { Contribution }\end{array}$ \\
\hline TON & 2 & 0.283799 & 0.1419 & 578.56 & $0.002^{*}$ & 63.90 \\
TOFF & 2 & 0.019741 & 0.009871 & 40.25 & $0.024^{*}$ & 4.50 \\
SV & 2 & 0.056609 & 0.028304 & 115.4 & $0.009^{*}$ & 13.00 \\
IP & 2 & 0.017537 & 0.008769 & 35.75 & $0.027^{*}$ & 4.00 \\
WF & 2 & 0.003793 & 0.001897 & 7.73 & 0.115 & 0.90 \\
WT & 2 & 0.003637 & 0.001819 & 7.41 & 0.119 & 0.80 \\
TON*TOFF & 4 & 0.008867 & 0.002217 & 9.04 & 0.102 & 2.00 \\
TON*SV & 4 & 0.037624 & 0.009406 & 38.35 & $0.026^{*}$ & 8.50 \\
TOFF*SV & 4 & 0.011048 & 0.002762 & 11.26 & 0.083 & 2.50 \\
Residual & 2 & 0.000491 & 0.000245 & & & \\
Error & & & & & 0.10 \\
Total & 26 & 0.443147 & & & \\
\hline \multicolumn{7}{c}{$*$ P-value $<0.05$ indicates significant factor at 95\% confidence level } \\
\hline
\end{tabular}


The percentage contribution of each variable influencing GRS is shown in Figure 11. It is clear that the primary influencing factor is pulse on period (contributing 63.80\%), followed by discharge voltage (adding 13.00\%), pulse off interval (contributing 4.50\%) and discharge current (providing $4.00 \%$ ). The influence of wire feed speed and cable tension is found to be negligible. Also, the percentage contribution of interaction between pulse on period and discharge voltage (contributing $8.50 \%$ ) found to be considerable as compared to other relations.

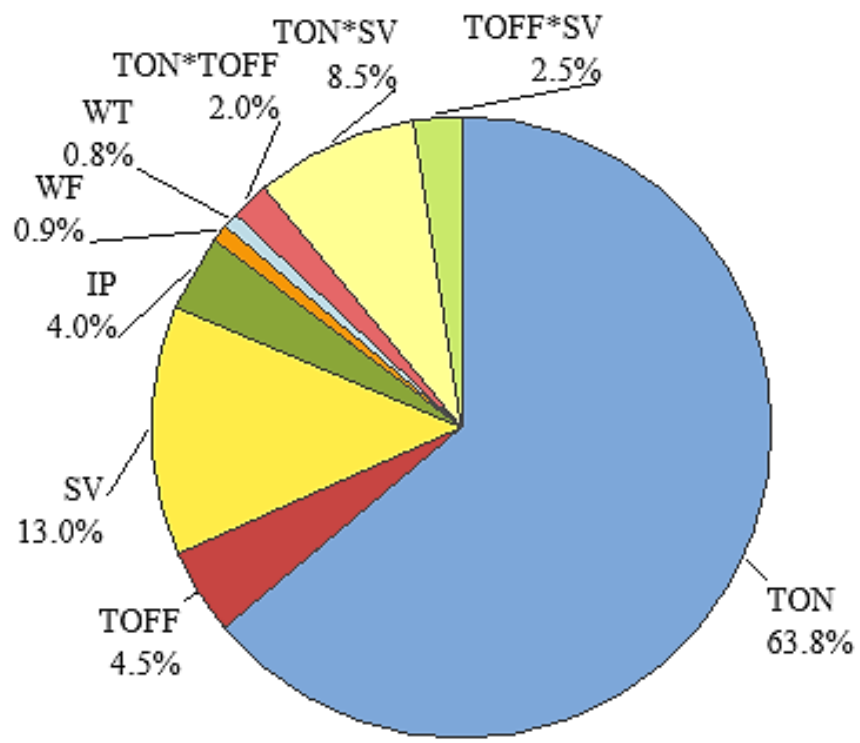

Figure 11. Pie chart of showing \% age contribution of parameters on GRS.

By using optimum arrangement, $\mathrm{TON}_{1} \mathrm{TOFF}_{3} \mathrm{SV}_{3} \mathrm{IP}_{1} \mathrm{WF}_{2} \mathrm{WT}_{3}$ confirmation trials are completed, and related values are shown in Table 13. These values signify that there is an enhancement in the grey relational score from 0.9048 to 0.9226 indicating improvement in the process.

Table 13. Confirmation experimental results at optimal setting.

\begin{tabular}{|c|c|c|}
\hline \multirow[t]{2}{*}{ Responses } & Predicted value & Experimental value \\
\hline & TON $_{1} T O F F_{3} S V_{3} I_{1} W_{2} W_{2}$ & TON $_{1} T O F F_{3} S V_{3} I_{1} W_{2} W_{2} T_{3}$ \\
\hline $\mathrm{W} 1(\mathrm{~mm})$ & 0.252 & 0.251 \\
\hline $\mathrm{W} 2(\mathrm{~mm})$ & 0.264 & 0.262 \\
\hline $\mathrm{W} 3(\mathrm{~mm})$ & 0.302 & 0.299 \\
\hline $\mathrm{W} 4(\mathrm{~mm})$ & 0.706 & 0.703 \\
\hline \multicolumn{3}{|l|}{ Surface Roughness } \\
\hline$(\mu \mathrm{m})$ & 1.35 & 1.28 \\
\hline Overcut (mm) & 0.157 & 0.148 \\
\hline $\operatorname{MRR}\left(\mathrm{mm}^{3} / \mathrm{min}\right)$ & 17.06 & 19.37 \\
\hline GRG & 0.9048 & 0.9226 \\
\hline
\end{tabular}




\section{Microstructure (Surface Roughness) Analysis of Machined Samples}

Figure 12 shows the microstructures of machined workpieces at low and high values of discharge energy. Discharge energy is the energy produced by a single spark which is converted into heat. The discharge energy primarily depends upon the pulse on period, discharge current and discharge voltage [26]. It shows craters, globules of debris, spherical particles, micro-cracks, melt drops, voids and matt surface appearance.

As the value of the discharge current increases density of sparks; hence thermal energy increases resulting in a rise in temperature up to $12000^{\circ} \mathrm{C}$. This result in local melting and vaporization of material and more amount of molten metal is ejected from the crater as these flashes strike the workpiece surface with more impulsive force. Hence large deep cavities are formed on the machined surface. As pulse on period increases, more amount of heat is transferred into the workpiece and results in the decrease of plasma flushing efficiency. This results in the reduction of spark energy density and impulsive force. Thus the dimension of the molten crater increases resulting in resolidification of molten metal in the form of recast layer as molten metal is not thoroughly washed out [27-28]. During the WEDM process due to rapid heating and cooling process, thermal stresses are produced, and micro cracks are formed on the workpiece surface [29]. All these factors lead to the more average surface finish. At low values of discharge energy during machining results in the smaller size of craters resulting in improvement of surface finish.

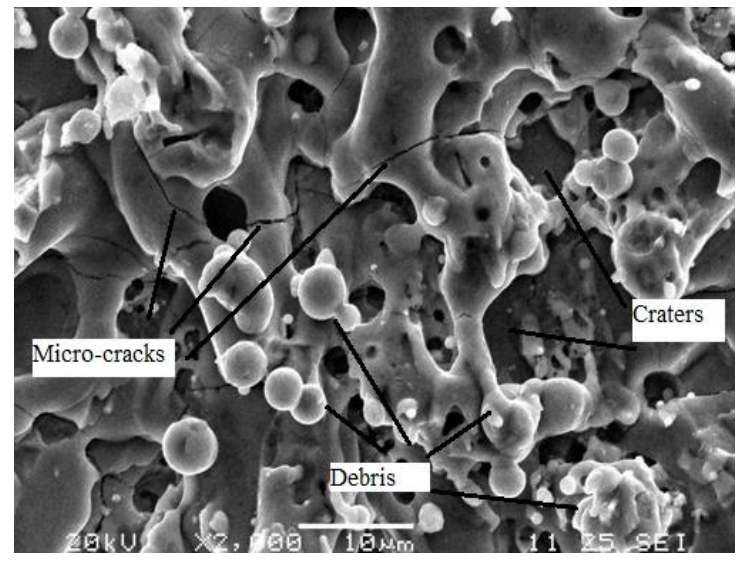

(a)

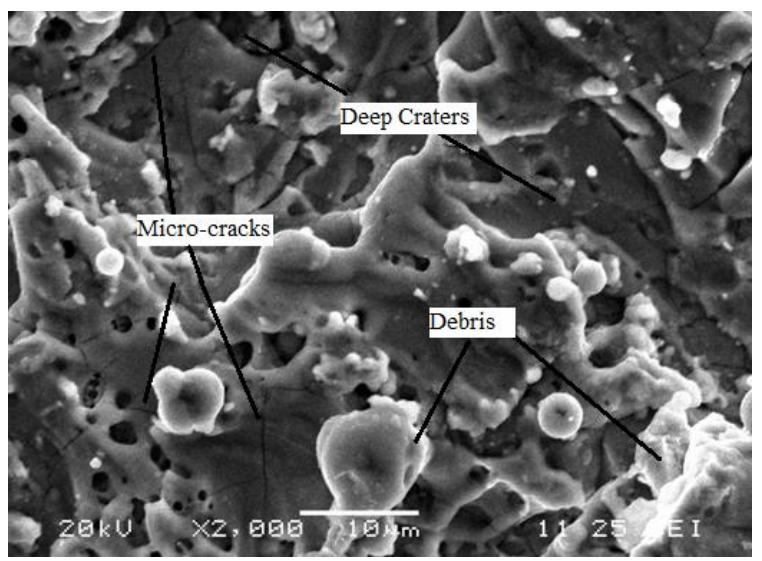

(b)

Figure 12. SEM Micrographs of Ti-6Al-4V (a) at low discharge energy (Exp. No.9), (b) at high discharge energy (Exp. No. 19)

\section{Development of Regression Equations}

From the experimental outcomes, mathematical relationships are developed between governing parameters and performance characteristics. The mathematical models are developed using multiple regression analysis method. For this analysis, Minitab 16 software is used to test user-defined linear models. The multiple regression coefficients $\left(\mathrm{R}^{2}\right)$ of all the equations are found to be above $85 \%$ suggesting the adequacy of the model above $85 \%$. These equations can be used to find out the values of the performance characteristics at the specified operating conditions $[14,16]$. The regression equations for the various response characteristics are as follows: 


$$
\begin{aligned}
& \mathbf{W 1}=-0.180+0.00411 \text { TON }-0.000700 \text { TOFF }-0.000661 S V+0.000278 I P-0.00186 \\
& W F-0.000444 W T \\
& \mathrm{~S}=0.00718686 \quad \mathrm{R}-\mathrm{Sq}=86.7 \% \quad \mathrm{R}-\mathrm{Sq}(\operatorname{adj})=82.7 \% \\
& \mathbf{W} 2=-0.276+0.00519 \text { TON }-0.000956 \text { TOFF }-0.000900 S V+0.000369 I P-0.00236 \\
& W F-0.000481 W T \\
& \mathrm{~S}=0.00844317 \quad \mathrm{R}-\mathrm{Sq}=88.6 \% \quad \mathrm{R}-\mathrm{Sq}(\operatorname{adj})=85.2 \% \\
& \mathbf{W 3}=-0.371+0.00650 \text { TON }-0.00126 \text { TOFF }-0.00111 S V+0.000467 I P-0.00258 W F- \\
& 0.000704 W T \\
& \mathrm{~S}=0.0103694 \quad \mathrm{R}-\mathrm{Sq}=88.9 \% \quad \mathrm{R}-\mathrm{Sq}(\operatorname{adj})=85.6 \% \\
& \mathbf{W 4}=0.153+0.00526 \text { TON }-0.00102 \text { TOFF }-0.000906 S V+0.000417 \text { IP }-0.00253 \text { WF }- \\
& 0.000463 W T \\
& \mathrm{~S}=0.00831420 \quad \mathrm{R}-\mathrm{Sq}=89.4 \% \quad \mathrm{R}-\mathrm{Sq}(\operatorname{adj})=86.2 \% \\
& \mathbf{S R}=-7.21+0.0808 \text { TON }-0.0144 \text { TOFF }-0.0137 \text { SV + 0.00628 IP }-0.0389 \text { WF }-0.00778 \\
& W T \\
& \mathrm{~S}=0.122433 \quad \mathrm{R}-\mathrm{Sq}=90.1 \% \quad \mathrm{R}-\mathrm{Sq}(\mathrm{adj})=87.1 \% \\
& \text { Overcut }=0.0235+0.00128 \text { TON }-0.000250 \text { TOFF }-0.000236 S V+0.000096 I P- \\
& 0.000583 W F-0.000074 W T \\
& \mathrm{~S}=0.00190564 \quad \mathrm{R}-\mathrm{Sq}=90.5 \% \quad \mathrm{R}-\mathrm{Sq}(\operatorname{adj})=87.7 \% \\
& \text { MRR }=-105+1.13 \text { TON }-0.176 \text { TOFF }-0.170 S V+0.0864 \text { IP }-0.520 \text { WF }-0.099 F \\
& \mathrm{~S}=0.00190564 \quad \mathrm{R}-\mathrm{Sq}=90.5 \% \quad \mathrm{R}-\mathrm{Sq}(\operatorname{adj})=87.7 \%
\end{aligned}
$$

\section{CONCLUSIONS}

The conclusions from the present research work are as follows:

1. Pulse on period, pulse off interval, discharge voltage, discharge current, and wire feed speed mainly affect kerf width and MRR.

2. Surface roughness is primarily influenced by pulse on period, discharge current, discharge voltage and wire feed speed.

3. Overcut is mainly affected by pulse on period, discharge voltage and cable tension.

4. By applying GRI technique, the optimal combination of governing variables has been set with $\mathrm{TON}_{1}(110), \mathrm{TOFF}_{3}(55), \mathrm{SV}_{3}(40), \mathrm{IP}_{1}(170), \mathrm{WF}_{2}(3), \mathrm{WT}_{3}(8)$ which gives the highest grade value. An increase in the value of GRS from 0.9048 to 0.9226 indicates an enhancement in the performance of WEDM process using optimum values of governing parameters.

5. Pulse-on period is the primary factor affecting the grey relational score.

6. Microstructure analysis shows that with an increase in pulse on period and discharge current, large volume of heat energy released during machining which results in deep 
craters, globules of debris, voids and micro cracks thus deteriorating the surface finish.

7. Mathematical models are developed between governing variables and performance characteristics using a regression analysis method, which can be used to determine the values of the quality characteristics at different values of input parameters

\section{REFERENCES}

[1] Ho KH, Newman ST, Rahimifard S, Allen RD. State of the art in Wire electrical discharge machining (WEDM). International Journal of Machine Tools Manufacture. 2004; 44: 1247-1259.

[2] Jose J, Shunmugum MS. Investigation into white layer formed on wire electrical discharged machined TI6Al4V surface. International Journal of Machining and Machinability of Materials. 2009; 6: 234-249.

[3] Pasam VK, Battula SB, MadarValli P, Swapna M. Optimizing Surface Finish in WEDM Using the Taguchi Parameter Design Method. Journal of the Brazilian Society of Mechanical Sciences and Engineering. 2010; 49: 155-166.

[4] Jabbaripour B, Sadeghi MH, Faridvand S, Shabgard MR. Investigating the effects of EDM parameters on surface integrity, MRR, and TWR in machining of Ti-6Al-4V. Machining Science and Technology: An International Journal. 2012; 16: 419-444.

[5] Kumar A, Kumar V, Kumar J. Multi-response optimization of process parameters based on response surface methodology for pure titanium using WEDM process. International Journal of Advanced Manufacturing Technology. 2013; 68: 2645-2668.

[6] Chalisgaonkar R, Kumar J. Optimization of WEDM process of pure titanium with multiple performance characteristics using Taguchi's DOE approach and utility concept. Frontiers of Mechanical Engineering. 2013; 8: 201-214.

[7] Garg MP, Jain A, Bhushan G. Multi-objective optimization of process parameters in wire electrical discharge machining of Ti-6-2-4-2 alloy. Arabian Journal of Science and Engineering. 2014; 39: 1465-1476.

[8] Ghodsiyeh D, Golshan A, Izman S. Multi-objective process optimization of wire electrical discharge machining based on response surface methodology. International Journal of Advanced Manufacturing Technology. 2014; 36: 301-313.

[9] Sivaprakasam P, Hariharan P. Gowri, S. Modeling, and analysis of the micro-WEDM process of titanium alloy (Ti-6Al-4V) using response surface approach. Engineering Science and Technology an International Journal. 2014; 17: 227-235.

[10] Ramamurthy A, Sivaramakrishnan R, Muthumaramalingam T, Venugopal S. Taguchi-grey computation methodology for optimum multiple performance measures on machining titanium alloy in WEDM process. Indian Journal of Engineering and Materials Sciences. 2015; 22: 181-186.

[11] Kuriachen B, Somashekhar KP, Mathew J. Multiresponse optimization of wire electrical discharge machining process. International Journal of Advanced Manufacturing Technology. 2015; 76: 91-104.

[12] Majumdar H, Maity K. Optimization of Machining condition in WEDM for titanium grade 6 using MOORA coupled with PCA-A multivariate hybrid approach. Journal of Advanced Manufacturing Systems. 2017; 16: 81-99. 
[13] Raj S, Prabhu, S. Modeling and analysis of Titanium alloy in wire-cut EDM using grey relational coupled with principal component analysis. Australian Journal of Mechanical Engineering. 2017; 15: 198-209.

[14] Pujara JM, Kothari KD, Gohil AV. An investigation of material removal rate and kerf on WEDM through grey relational analysis. Journal of Mechanical Engineering and Sciences. 2018; 12: 3633-3644.

[15] Devarajaiah D, Muthumari C. Evaluation of power consumption and MRR in WEDM of Ti-6Al-4V alloy and its simultaneous optimization for sustainable production. Journal of the Brazilian Society of Mechanical Sciences and Engineering. 2018; 40: $1-18$.

[16] Ali MY, Banu A, Salehan M, Adesta EYT, Hazza M, Shaffiq M. Dimensional accuracy in Dry Micro wire Electrical Discharge Machining. Journal of Mechanical Engineering and Sciences. 2018; 12: 3321-3329.

[17] Manjaiah M, Narendranath S, Basavrajappa S. A Review on machining of titanium Based alloys using EDM and WEDM. Reviews on Advanced Materials Science. 2014; 36: 89-111.

[18] Ezugwu EO, Wang ZM. Titanium alloys and their machinability-a review. Journal of Materials Processing Technology. 1997; 68: 262-274.

[19] Guitrau B. The EDM Handbook. Hansen Gardner Publications, Cincinnati, OH, 1997; 174.

[20] Sharma N, Khanna R, Gupta RD. WEDM process variables investigation for HSLA by response surface methodology and genetic algorithm. Engineering Science and Technology an International Journal. 2015; 18: 171-177.

[21] Tosun N, Cogun C, Tosun G. A study on kerf and material removal rate in wire electrical discharge machining based on Taguchi method. Journal of Materials Processing Technology. 2004; 152: 316-322.

[22] Sharma P, Chakradhar D, Narendranath S. Evaluation of WEDM performance characteristics of Inconel 706 for turbine disk application. Materials and Design. 2015; 88: 558-566.

[23] Sonawane S, Kulkarni M. Multi-quality characteristics optimization of WEDM for IN-625 by applying Taguchi DEAR technique. In: $1^{\text {st }}$ International Conference on Communication and Signal Processing, Lonere, pp. 1-6; 2017.

[24] Deng JL. Introduction to grey system theory. Journal of Grey System. 1989; 1: 1-24.

[25] Chang CL, Tsai CH, Chen L. Applying grey relational analysis to the decathlon evaluation model. International Journal of the Computer, the Internet and Management. 2003; 11: 54-62.

[26] Gostimirovic M, Kovac P, Sekulic M, Skoric B. Influence of discharge energy on machining characteristics in EDM. Journal of Mechanical Science and Technology. 2012; 26: 173-179.

[27] Srivastava V, Pandey MP. Effect of process parameters on the performance of the EDM process with ultrasonic assisted cryogenically cooled electrode. Journal of Manufacturing Process. 2012; 14: 393-402.

[28] Lee HT, Tai TY. Relationship between EDM parameters and surface crack formation. Journal of Materials Processing Technology. 2003; 142: 676-683.

[29] Hscalik A, Caydas U. Electric discharge machining of titanium alloy (Ti-6Al-4V). Applied Surface Science. 2007a; 253: 9007-9016. 